\title{
A New Metric to Diagnose Precipitation Distribution in Transitioning Tropical Cyclones
}

\author{
AJAY RAGHAVENDRA \\ Department of Atmospheric and Environmental Sciences \\ University at Albany, Albany, New York \\ SHAWN M. MILRAD \\ Meteorology Program, Applied Aviation Sciences Department \\ Embry-Riddle Aeronautical University, Daytona Beach, Florida
}

(Manuscript received 23 August 2018; revised 5 March 2019; review completed 11 March 2019)

\begin{abstract}
A new coupled dynamic and thermodynamic metric is developed based on the Eady Moist Baroclinic Growth Rate (EMBGR), to discriminate between left-of-track (LOT) and right-of-track (ROT) precipitation distributions in transitioning tropical cyclones (TCs). LOT events pose a major flood risk even when a TC tracks along a coastline or just offshore, as flash flooding can occur hundreds of kilometers inland from the cyclone center. The EMBGR can improve human-produced quantitative precipitation forecasts (QPF) because it is dependent on relatively well-forecast large-scale mass fields. The ability of the EMBGR to identify precipitation distribution is first explored in a case study of TC Matthew (2016), using reanalysis and numerical model forecasts. Subsequently, a composite analysis of 36 years (1979-2014) of United States landfalling TCs using reanalysis data shows that the EMBGR is an effective discriminator between LOT and ROT distributions. The utility of the EMBGR is quantified using a pattern correlation analysis for both TC Matthew and the composites. Finally, a conceptual schematic is developed for LOT cases so that forecasters can most effectively utilize the EMBGR to improve human QPF skill during transitioning TCs.
\end{abstract}

\section{Introduction}

Nearly $50 \%$ of tropical cyclones (TCs) in the North Atlantic basin undergo extratropical transition (ET, Hart and Evans 2001). Re-intensifying ET events can result in an expansion of the cyclone wind field (Evans and Hart 2008; Evans et al. 2017) and the heaviest precipitation shifting to left-of-track (LOT, Atallah et al. 2003, 2007; Milrad et al. 2009). From a precipitation perspective, LOT events often cause inland flash flooding hundreds of kilometers from the cyclone center (Hart et al. 2006; Atallah et al. 2007; Milrad et al. 2009; Evans et al. 2017). Recent LOT cases such as Matthew (2016), Sandy (2012; e.g., Galarneau et al. 2013), and Irene (2011) were associated with substantial loss of life and billions of dollars in damage. Irene (2011) caused over 10 billion USD in damage and 45 deaths (NOAA NCEI
2018), the majority of which occurred due to freshwater flash flooding in upstate New York and Vermont, where $175-300 \mathrm{~mm}$ of rain fell on already saturated soil (Vermont Agency of Natural Resources 2018). It was the worst natural disaster in Vermont history, resulting in more than $800 \mathrm{~km}$ of damaged roads, 200 damaged bridges, 73,000 power outages, 20,000 acres of flooded farmland, and communities completely cutoff for weeks. In 2016, TC Matthew resulted in $\sim 400 \mathrm{~mm}$ of precipitation in parts of the Carolinas (Fig. 1a), causing extensive freshwater flooding (section 3 ).

In this study we propose a new metric to diagnose and predict precipitation distribution and the location of heaviest precipitation in transitioning TCs, with the objective being to improve human-produced quantitative precipitation forecasts (QPF). $\mathrm{QPF}$ remains an important challenge, especially during

Corresponding author address: Shawn M. Milrad, Meteorology Program, Embry-Riddle Aeronautical University, 600 S. Clyde Morris Blvd, Daytona Beach, FL 32114

E-mail: milrads@erau.edu 


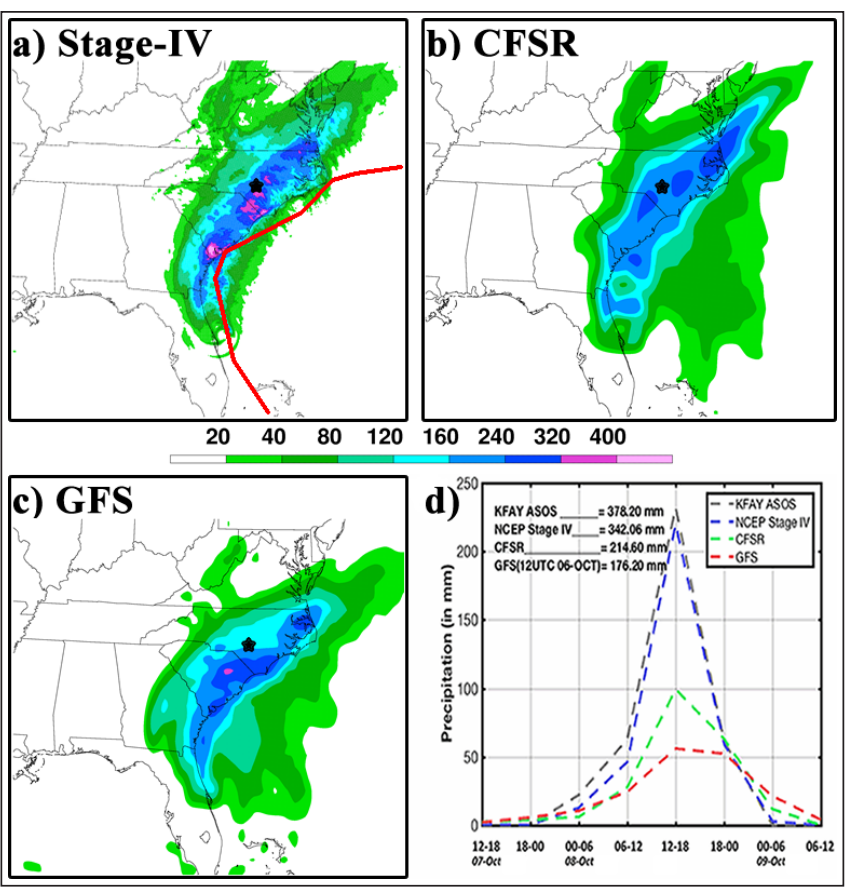

Figure 1. 48-h total accumulated precipitation (mm, shaded) for 1200 UTC 7 October-1200 UTC 9 October 2016 from (a) NCEP Stage-IV, (b) CFSR, and (c) the 1200 UTC 6 October 2016 GFS forecast. The observed track of Hurricane Matthew (2016) based on HURDAT2 (Landsea and Franklin 2013) is marked by the solid red line in (a) and Fayetteville, NC (KFAY) is marked with a black star in (a-c). (d) accumulated precipitation $(\mathrm{mm})$ for every $6-\mathrm{h}$ period from: the KFAY ASOS (black dashed), a $1^{\circ} \times 1^{\circ}$ grid-averaged box around KFAY using NCEP Stage-IV (blue dashed), CFSR (green dashed), and the 1200 UTC 6 October 2016 GFS forecast (red dashed); the totals written in black text are the integrated areas under each line. Click image for an external version; this applies to all figures hereafter.

extreme events (Sisson and Gyakum 2004; Milrad et al. 2009). Roebber and Bosart (1998) and Sisson and Gyakum (2004) pointed out that while forecast skill of mass fields (e.g., 500-hPa geopotential height, wind, temperature) has greatly improved, QPF skill still lags behind. Sukovich et al. (2014) showed that in extreme ( $\geq 25.4 \mathrm{~mm}$ in $\leq 24 \mathrm{~h}$ ) precipitation events, humanproduced QPF at the National Weather Service Weather Prediction Center, which is ostensibly influenced by mass field forecasts, is more skillful than modelproduced QPF by $30-40 \%$. This is particularly true in the warm season, when convective precipitation is often a large component of QPF (Fritsch and Carbone
2004). As such, a greater understanding of mass field precursors and characteristics of heavy precipitation events, such as those associated with transitioning TCs, can lead to better human QPF skill.

Our focus in this study is on United States landfalling TCs that move poleward and exhibit a precipitation distribution shift to LOT or right-of-track (ROT). We used the following criteria to define LOT and ROT cases:

- The TC was required to move at least 500 $\mathrm{km}$ poleward after landfall. Although there have been various definitions for time of ET (Evans et al. 2017), poleward motion was required to ensure that transitioning TCs were included, following Atallah et al. (2007).

- For a transitioning TC to be classified as LOT or ROT, $>50 \%$ of the total reanalysis precipitation within a $5^{\circ} \times 5^{\circ}$ box around the TC center at a 6-h time step had to be LOT or ROT. This criterion also follows Atallah et al. (2007).

- The precipitation shift to LOT or ROT had to last a minimum of $12 \mathrm{~h}$.

Figure 2 shows storm tracks and precipitation (NWS WPC 2018) for two LOT (Jeanne 2004; Ike 2008) and two ROT cases (Lili 2002; Isaac 2012) included in our composite analysis (section 4). The use of LOT and ROT here refers to the shift in precipitation distribution as each TC moves poleward and loses its tropical characteristics. In a typical TC, the heaviest precipitation is typically found to the left of the vertical wind shear vector (e.g., Lonfat et al. 2004; Chen et al. 2006), which is primarily ROT in the North Atlantic Basin (Evans et al. 2017). Jeanne (2004) and Ike (2008) exhibit precipitation distributions that shift LOT as the transitioning TCs moved poleward, resulting in $>$ $125 \mathrm{~mm}$ of rainfall across parts of the Northeast and Midwest United States, respectively (Figs. 2a,c). Atallah et al. (2007) and Milrad et al. (2009) also found that the heaviest precipitation in LOT cases is generally located near the back-bent warm front in the northwest quadrant of the surface cyclone, observed for Jeanne (2004) and Ike (2008) in Figs. 2a,c. In contrast, Lili (2002) and Isaac (2012) generally exhibit ROT precipitation distributions as they move slowly northward through Louisiana and Arkansas (Figs. 2b,d). The precipitation 


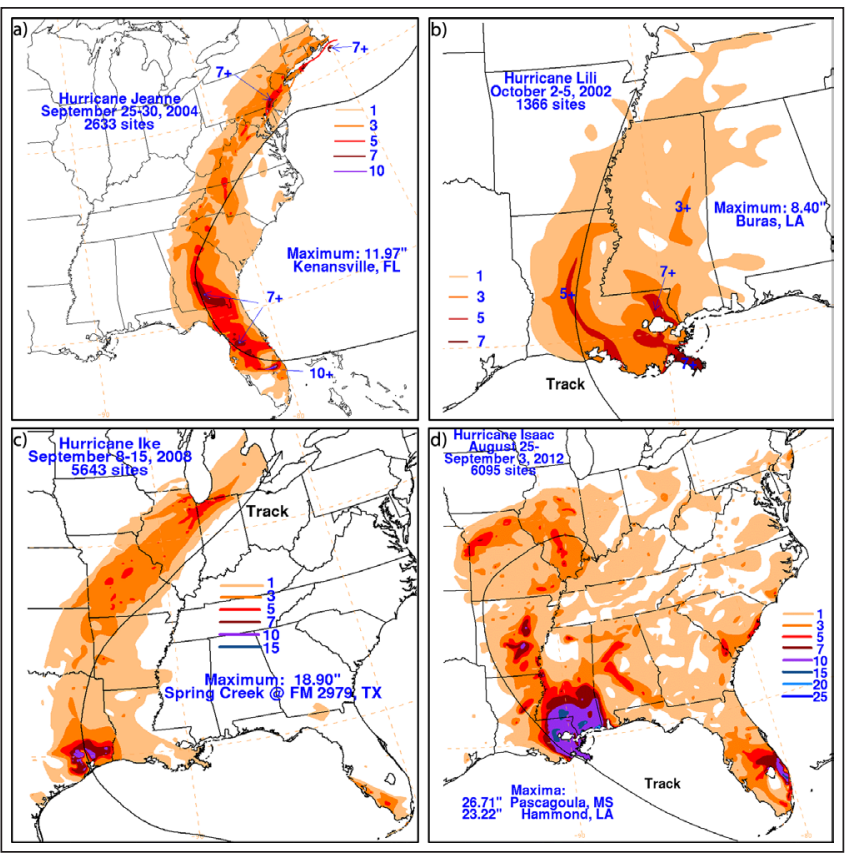

Figure 2. Adapted from NWS WPC (2018). Total event precipitation (in., shaded, 1 in. $=25.4 \mathrm{~mm}$ ) from two LOT and two ROT cases in this study: (a) Jeanne (2004; LOT), (b) Lili (2002; ROT), (c) Ike (2008; LOT), and (d) Isaac (2012; ROT). The black line in each panel represents the track of each TC from HURDAT2 (Landsea and Franklin 2013).

over Missouri and central Illinois during Lili (2002) was associated with a mid-tropospheric trough to the west that failed to fully interact with the TC (not shown). Moreover, precipitation amounts generally decrease as Lili (2002) and Isaac (2012) move slowly poleward, which is typical of ROT cases (Atallah et al. 2007; Milrad et al. 2009).

Most previous ET metrics have investigated onset time and storm evolution, not precipitation. The Cyclone Phase Space (Hart 2003; Evans and Hart 2003), which is generally accepted as the best existing tool to diagnose ET from gridded datasets (Evans et al. 2017), defined ET onset as the time the storm first becomes asymmetric in the lower-troposphere (900-600-hPa layer), with ET concluding when the storm becomes cold-core (Evans et al. 2017). Hart et al. (2006) further analyzed the differences between re-intensifying ET events and TCs that decay after ET begins; to do so, they defined ET onset as the first time that a TC becomes asymmetric in the Cyclone Phase Space. For a complete overview of ET time and intensity metrics, the reader is referred to the review paper by Evans et al. (2017).
In this study, we propose to use the Eady Moist Baroclinic Growth Rate (EMBGR) to diagnose precipitation distribution in transitioning TCs. The EMBGR is not intended as an ET time or intensity discriminator. Instead, it focuses on a single impact: the distribution of the heaviest precipitation relative to the transitioning TC track. During transition, precipitation distribution shifts either LOT or ROT, which can have profound impacts on QPF and flooding potential (Atallah and Bosart 2003; Atallah et al. 2007; Milrad et al. 2009; Evans et al. 2017). Important aspects of the EMBGR metric detailed in this study are:

- It focuses on a single impact of transitioning TCs: rainfall due to a shift in precipitation distribution. Typically, LOT cases result in greater flooding and impacts to life and property because they feature larger precipitation amounts over a larger spatial extent than ROT cases (Atallah et al. 2007). In addition, LOT cases can track along or just off the eastern seaboard of North America and still produce heavy precipitation on land (e.g., Atallah and Bosart 2003; Atallah et al. 2007; Milrad et al. 2009).

- It does not a priori make any assumptions about whether the TC has undergone or is undergoing ET, or whether it will re-intensify. Given that there is not a universal definition of time or intensity of ET (Evans et al. 2017), we focus on how the EMBGR can diagnose the location of the heaviest precipitation relative to the transitioning TC track. Henceforth we primarily use the term 'transitioning TC' instead of 'ET', so as not to cause confusion with studies (e.g., Hart 2003; Kofron et al. 2010a,b) that aim to diagnose ET time and/or intensity.

- It incorporates static stability, which is crucial to determining the location and relative intensity of the heaviest precipitation (e.g., Gyakum 2008).

- It utilizes synoptic-scale environmental characteristics to diagnose precipitation distribution, relying little on TC structure and dynamics, which are typically not wellresolved by operational global or mesoscale numerical models. We acknowledge, however, 
that within deep moist convection, stability parameters incorporated into the EMBGR can be affected by model convective parameterization schemes.

The remainder of the paper is organized as follows: section $2 \mathrm{a}$ describes the data and techniques used to choose the cases for the study, while section $2 b$ defines the EMBGR metric. Section 3 details a case study of Matthew (2016), while section 4 presents composite results. Finally, a discussion, conceptual schematic, and conclusions are detailed in section 5.

\section{Data and metric}

\section{a. Data}

The National Centers for Environmental Prediction (NCEP) Climate Forecast System Reanalysis (CFSR), which is run at T382 spectral resolution $(\sim 38 \mathrm{~km})$ and obtained on a $0.5^{\circ}$ global grid with a 6-h temporal resolution (Saha et al. 2010), was used for our case study of TC Matthew (section 3) and composite analysis (section 4). The NCEP CFSR is available for 1979-2011 and has been shown to reliably reproduce precipitation (Saha et al. 2010). Since 2011, the CFSR has been extended in real-time as the identical NCEP Climate Forecast System Version 2 (CFSv2, Saha et al. 2014). To avoid confusion, both datasets are referred to here as CFSR. To ensure reliability, CFSR precipitation was compared with the higher-resolution and rain gauge-based NCEP North American Regional Reanalysis (NARR; Mesinger et al. 2006) and NCEP Stage-IV (Lin and Mitchell 2005) datasets and found to be qualitatively similar (e.g., Fig. 1).

For our case study of TC Matthew (2016), we used NCEP Stage-IV precipitation to validate the GFS and CFSR results. NCEP Stage-IV is an hourly product with a 4-km grid spacing and incorporates radar and rain gauge observations over the contiguous United States (Lin and Mitchell 2005), limiting its utility offshore. However, it was accurate for TC Matthew because of the limited extent of offshore precipitation. To verify this point, we compared Stage-IV accumulations with The Integrated Multisatellite Retrievals for Global Precipitation Measurement (IMERG; Huffman et al. 2015), which incorporates observations from several satellites, and found them to be quite similar in terms of spatial precipitation distribution (i.e., LOT) and maximum accumulation.
While the NARR (32-km grid spacing, 3-h temporal resolution) and NCEP Stage-IV have finer spatial and temporal resolution, the global CFSR is more reliable for large-scale dynamic and thermodynamic fields (Saha et al. 2010; 2014). Therefore, we use it for the entirety of our composite analysis (section 4). We also wanted to demonstrate that a global reanalysis can be useful to diagnose the EMBGR, so that it may be applied to other TC basins. However, since the NARR and NCEP Stage-IV were used for precipitation qualitycontrol purposes, we limited our cases to United States landfalling TCs.

For Matthew (2016), we also utilized the $0.5^{\circ}$ NCEP Global Forecast System (GFS) forecasts. The $0.5^{\circ}$ GFS was used instead of the $0.25^{\circ}$ GFS so that the grid spacings of the CFSR and GFS were identical. Finally, track data used to produce the composite Cyclone Phase Space diagrams (section 4) were obtained from HURDAT2 (Landsea and Franklin 2013), while TC positions in the CFSR were determined by the location of the mean sea-level pressure (MSLP) cyclone center. There were occasionally very minor differences between CFSR and HURDAT2 TC positions that could slightly impact the Cyclone Phase Space diagrams, but they did not affect our conclusions.

Most graphics were created using the General Meteorological Package (GEMPAK) version 7.4.1, updated from the original package of Koch et al. (1983). The Cyclone Phase Space diagrams were produced using the Grid Analysis and Display System (GrADS, Doty and Kinter III 1992) and publicly-available code written by Hart (2003). The correlation diagnostics presented in sections 3 and 5 were calculated using the NCAR Command Language version 6.5.0 (The NCAR Command Language 2018).

\section{b. EMBGR metric}

Gyakum (2008) pointed out that heavy synopticscale precipitation is typically caused by strong ascentforcing from baroclinic processes, in the presence of low static stability. As TCs move poleward into the mid-latitudes and undergo transition, baroclinicity becomes more important to the distribution and location of associated heavy precipitation. Because the EMBGR incorporates baroclinicity and static stability, it can be used as a proxy metric for precipitation distribution in transitioning TCs. 
To derive the EMBGR, consider the Eady baroclinic growth rate (Eady 1949), defined by Hoskins and Valdes (1990):

$$
\sigma_{B I}=0.31 f \partial \vec{v} / \partial z N^{-1},
$$

where $f$ is the Coriolis parameter, $\partial \vec{v} / \partial z$ is vertical wind shear, and $N$ is Brunt-Väisälä frequency. While Eq. (1) measures baroclinicity and static stability, it also assumes that the atmosphere is unsaturated, which is not ideal for situations involving heavy precipitation. Equation (1) can be modified by using a simplified version of the Moist Brunt-Väisälä Frequency $\left(N_{m}\right.$, hereafter MBVF) discussed by Fraser et al. (1973) and Durran and Klemp (1982). In Eq. (2), $N_{m}$ accounts for saturated air parcels by incorporating the moist adiabatic lapse rate $\left(\Gamma_{m}\right)$ for a lifted parcel:

$$
\mathrm{N}_{m}^{2}=g / T\left(d T / d z+\Gamma_{m}\right)
$$

where $g$ is acceleration due to gravity, $T$ is the environmental temperature averaged over the layer in which the moist adiabatic lapse rate is calculated, and $z$ is height. Durran and Klemp (1982) noted that Eq. (2) produces reasonably accurate numerical results, but substantial errors may result when static stability is small.

Substituting $N_{m}$ for $N$ in Eq. (1) and using the magnitude of vertical wind shear allows us to define Eq. (3) as the EMBGR:

$$
E M B G R=0.31 f|\hat{o v} / \partial z| N_{m}^{-1} .
$$

Following Cordeira and Bosart (2010), we calculated the layer-averaged 850-600-hPa EMBGR, using 850600-hPa MBVF $\left(N_{m}\right)$ and vertical wind shear magnitude $|\partial \vec{v} / \partial z|$. The MBVF represents static stability and can be either positive or negative. A negative MBVF results in a complex $N_{m}$; provided that the layer is saturated, $N_{m}^{2}<0$ is evidence of a moist absolutely unstable layer (MAUL, Bryan and Fritsch 2000). To differentiate between EMBGR that is stable with respect to the moist adiabat for saturated conditions $\left(N_{m}^{2}>0\right.$, hereafter "stable EMBGR") and $N_{m}^{2}<0$ (hereafter "MAUL EMBGR"), stable EMBGR is shown in cool colors and MAUL EMBGR in warm colors.

Not much attention has been given to MAULs on the synoptic-scale because they typically exist in shallow layers during mesoscale convection (Bryan and
Fritsch 2000). However, work on extreme precipitation events (Milrad et al. 2015) found that MAULs can exist in relatively deep $(>100 \mathrm{hPa}$ ) vertical layers over a relatively wide geographical area. In this study, we show that MAUL EMBGR is typically found where moist convection is occurring within a transitioning TC. To ensure that MAUL EMBGR regions are associated with a saturated atmosphere, MAUL EMBGR is only plotted when the layer-averaged relative humidity is $\geq$ $90 \%$ in the $850-600-\mathrm{hPa}$ layer.

As shown by Eq. (3), the EMBGR incorporates baroclinity using vertical wind shear magnitude and measures static stability through the MBVF. As we demonstrate in sections 3 and 4, the combined EMBGR metric serves as an accurate proxy for precipitation distribution in transitioning TCs, enabling the forecaster with a tool that holds advantages over model QPF due to its large reliance on mass fields. In addition, the EMBGR is a better proxy than either of its individual components (section 4), illustrating its robustness.

\section{Results: TC Matthew (2016)}

TC Matthew (2016)'s track paralleled the southeast United States coast in October 2016, causing extensive damage to life and property. While the worst wind and storm surge impacts were primarily in Florida and Georgia, inland flooding due to extreme rainfall occurred in parts of the Carolinas, especially southeastern North Carolina. Figure 1a shows NCEP Stage-IV 48-h accumulated precipitation between 1200 UTC 7 October and 1200 UTC 9 October 2016, while Figs. $1 \mathrm{~b}$ and $1 \mathrm{c}$ show 48 -h precipitation for the same time period from the CFSR and 1200 UTC 6 October 2016 GFS, respectively. Other GFS runs (e.g., 0000 UTC 6 October) were tested and found to be similar with respect to both QPF and mass fields. Figure 1b shows that while CFSR underestimates the magnitude of the heaviest observed precipitation due to the resolution difference between Stage-IV and CFSR (not shown), the precipitation distribution and heaviest precipitation locations are quite similar (Fig. 1a). Compared to CFSR, the GFS under-forecast the heaviest rainfall by 40-80 $\mathrm{mm}$ throughout the flood region of southeastern North Carolina and northern South Carolina (Fig. 1c)

Figure 1d shows precipitation totals for Fayetteville, $\mathrm{NC}$, which was located in the hardest-hit flood region. According to Stage-IV data, Fayetteville, North Carolina (KFAY) saw a storm total of $342 \mathrm{~mm}$, which was similar to surface station observations $(378.2 \mathrm{~mm}$, 
Fig. 1d). Based on Stage-IV (Fig. 1a), CFSR (Fig. 1b), and IMERG data (not shown), it is evident that as the center of Matthew paralleled the eastern seaboard between Melbourne, Florida, and Cape Hatteras, North Carolina, the heaviest precipitation became increasingly LOT north of Georgia, resulting in the extreme rainfall totals over the Carolinas, particularly near KFAY.

To investigate the ability of the EMBGR to diagnose the precipitation distribution shift during Matthew, we used the CFSR and the 1200 UTC 6 October GFS. Figure 3 compares CFSR and GFS 6-h precipitation distribution to CFSR and GFS EMBGR at 1200 UTC 8 October, the start of the heaviest 6 -h precipitation period (Fig. 1b). Precipitation distribution clearly shifts LOT in the CFSR (Fig. 3b) as Matthew tracked along the coast (red line in Fig. 3b), with a maximum located near KFAY. In contrast, GFS precipitation distribution remains closer to the cyclone center and less LOT (Fig. 3d). EMBGR is LOT in both the CFSR and GFS (Figs. $3 \mathrm{a}, \mathrm{c})$, although there are substantial differences in the relative distributions of MAUL and stable EMGBR. MAUL EMBGR is a better match for the location of heaviest precipitation in the GFS, while stable EMBGR LOT in the GFS (Fig. 3c) is a better predictor of where the heaviest precipitation actually was (based on CFSR). We speculate that the discrepancy here is related to the location of moist convection in the GFS forecast, which influences where MAUL EMBGR is large. Figure 3 shows that while the CFSR EMBGR and precipitation distributions largely match (both LOT at 1200 UTC), GFS EMBGR does a better job than GFS QPF of suggesting the actual LOT precipitation shift over northern South Carolina and southern North Carolina.

To quantify the EMBGR's usefulness, we calculated Pearson product-moment correlation coefficients for a set of EMBGR and precipitation values. First, we found a 0.92 correlation between Stage-IV and CFSR (Figs. 1a,b) 48-h precipitation, suggesting that CFSR precipitation can be used as qualitative verification for the GFS forecasts. Next, we correlated CFSR with GFS precipitation, as well as both CFSR and GFS EMBGR with CFSR precipitation (Table 1), using the times shown in Fig. 3. Correlations between EMBGR and precipitation used the full EMBGR field (i.e., the total spatial extent of stable and MAUL EMBGR combined, not limited to any minimum EMBGR value). While stable and MAUL EMBGR are conceptually interesting on their own, their respective distributions vary with each case.

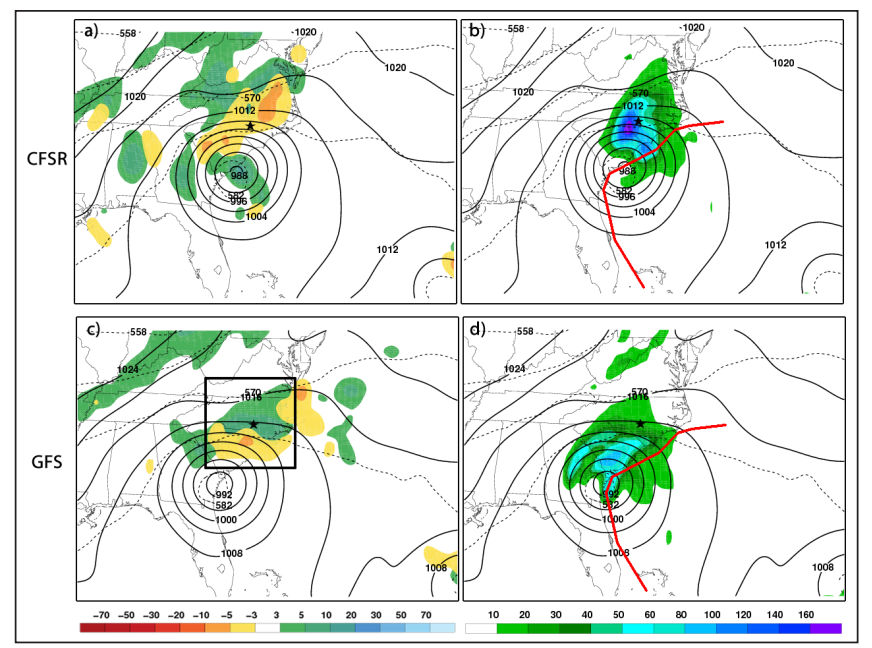

Figure 3. (left) EMBGR (x 10-6 day $^{-1}$, stable EMBGR shaded in cool colors and MAUL EMBGR in warm colors), MSLP (hPa, solid black contours), and 1000500-hPa thickness (dam, dashed black contours); (right) 6-h precipitation (mm, shaded), MSLP ( $\mathrm{hPa}$, solid black contours) and 1000-500-hPa thickness (dam, dashed black contours) for: $(a, b)$ CFSR at 1200 UTC 8 October, and (c,d) 1200 UTC 6 October 2016 GFS forecast verifying at 1200 UTC 8 October 2016. The 6-h precipitation shown in $(\mathrm{b}, \mathrm{d})$ is valid for $1200-1800$ UTC 8 October. The solid red lines in $(b, d)$ represent the track of TC Matthew from HURDAT2 (Landsea and Franklin 2013).

CFSR and GFS precipitation distributions exhibit a 0.65 correlation (Table 1), suggesting that the spatial distribution of GFS QPF was not entirely accurate. For correlations that spatially compare EMGBR to precipitation, the CFSR value (0.82) is substantially larger than the GFS value (0.47). Most importantly, GFS EMBGR has a larger correlation with CFSR precipitation $(0.73)$ than it does with GFS precipitation (0.47). This suggests that for TC Matthew, total EMBGR is a good proxy for precipitation distribution. As TC Matthew is only one case, these correlations are promising but motivate our composite analysis of nearly 50 cases (section 4); composite correlations are discussed in section 5 .

\section{Results: Composite analysis}

\section{a. Case identification}

North Atlantic basin TCs that made landfall in the contiguous United States from 1979-2014, inclusive, were considered. We limited cases to United States 
Table 1. Pearson product-moment correlation coefficients for TC Matthew (section 3). Each column header specifies which two fields in Fig. 3 are being correlated.

\begin{tabular}{|c|c|c|c|}
\hline $\begin{array}{c}\text { CFSR precipitation vs. } \\
\text { GFS precipitation }\end{array}$ & $\begin{array}{c}\text { CFSR EMBGR vs. } \\
\text { CFSR precipitation }\end{array}$ & $\begin{array}{c}\text { GFS EMBGR vs. } \\
\text { GFS precipitation }\end{array}$ & $\begin{array}{c}\text { GFS EMBGR vs. } \\
\text { CFSR precipitation }\end{array}$ \\
\hline 0.65 & 0.82 & 0.47 & 0.73 \\
\hline
\end{tabular}

landfalling TCs so that CFSR precipitation could be checked with a gauge-based dataset (i.e., NARR, NCEP Stage-IV). TC tracks were examined using HURDAT2 (Landsea and Franklin 2013) and the NOAA Coastal Services Center Historical Hurricane Tracks plotting tool (NOAA CSC 2018). We found that 117 TCs made a United States landfall during 1979-2014. For the LOT/ROT partitioning criteria detailed in section 1, 73 cases met the $500 \mathrm{~km}$ poleward criterion, 26 of which were classified as LOT and 22 as ROT (Table 2 ). The remaining 25 cases did not fit either category and were excluded from the composites. Of these 25 , five exhibited along-track precipitation and could not be definitively partitioned into LOT or ROT, and 19 cases did not exhibit a precipitation shift for at least 12 h. Finally, Arthur (1996) was excluded because of erroneous mass fields in the CFSR, particularly 500hPa geopotential height; as such, the EMBGR could not be accurately calculated. Mass fields of all other cases were found to be reasonable.

Figure 4 shows tracks (NOAA CSC 2018) of the 26 LOT (Fig. 4a) and 22 ROT (Fig. 4b) cases selected for composite analysis. LOT cases generally moved a larger distance poleward than the ROT cases (Fig. 4), consistent with past research and suggestive of stronger interactions with mid-tropospheric troughs (Hart et al. 2006; Atallah et al. 2007; Milrad et al. 2009; Evans et al. 2017). In contrast, ROT cases systematically exhibit an eastward component of motion, indicative of weaker TC-trough interactions (Harr and Elsberry 2000; Harr et al. 2000; Hart et al. 2006; Atallah et al. 2007; Milrad et al. 2009). These results are also consistent with Ritchie and Elsberry $(2003,2007)$, in which TCs that interact strongly with mid-latitude troughs (such as most LOT cases; e.g., Milrad et al. 2009) have a larger translation speed and therefore tend to move farther poleward.

\section{b. Grid-centered technique}

Because each transitioning TC has a different track (Fig. 4), a grid-centered composite technique was used. This technique overlays all cases on top of each other at each 6-h time step, and the composite track is the

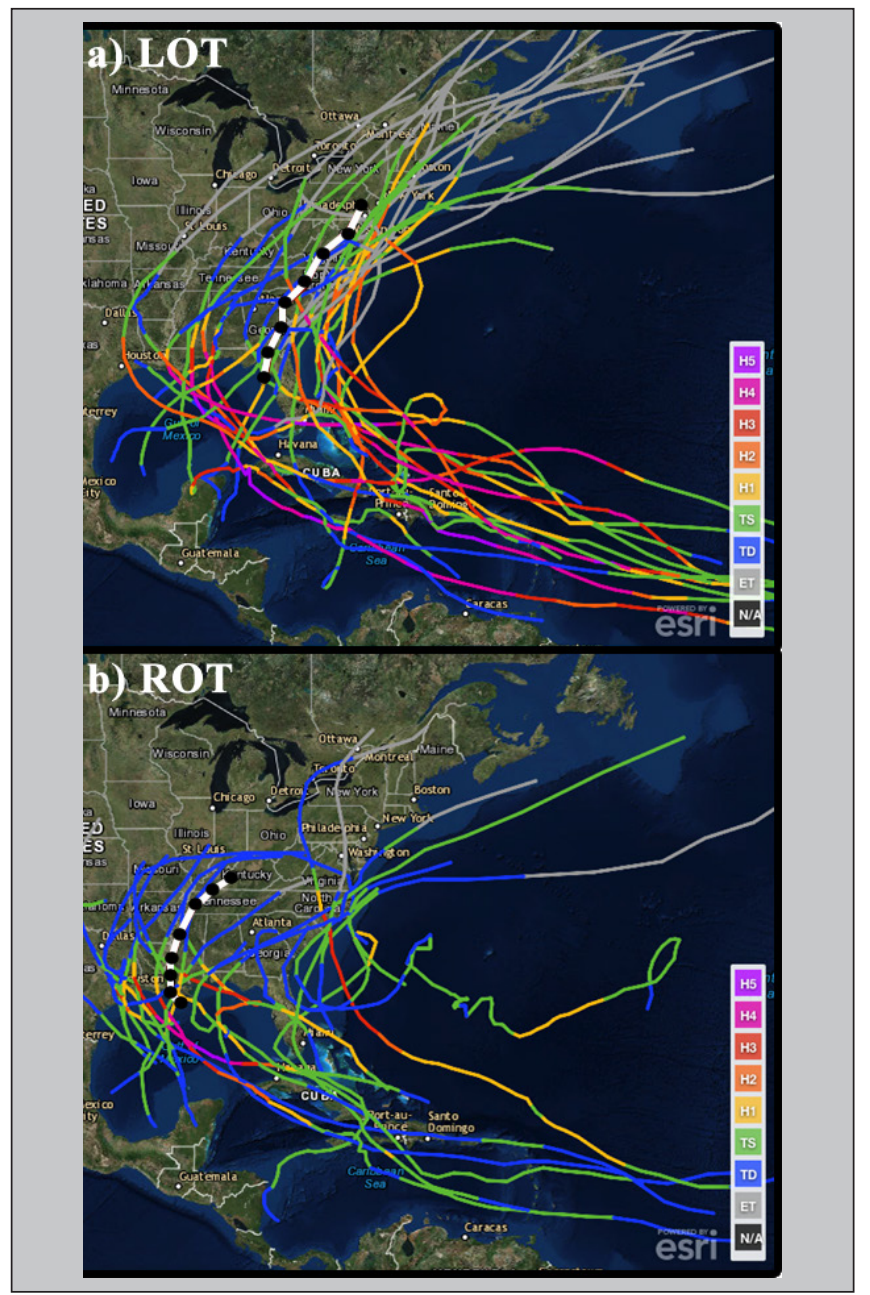

Figure 4. Full lifecycle tracks of the (a) 26 LOT and (b) 22 ROT cases in each composite, produced using the NOAA Coastal Services Center online plotting tool (NOAA CSC 2018). The bold white line in each panel represents the mean track used for the grid-centered composite analysis (section $4 \mathrm{~b}$ ), from $\mathrm{t}=-24 \mathrm{~h}$ to $\mathrm{t}=$ $+24 \mathrm{~h}$ with black dots every $6 \mathrm{~h}$. The color legend in the lower right corner of each panel represents TC intensity derived from HURDAT2 (Landsea and Franklin 2013), as follows: Category 5 hurricane (purple), category 4 (pink), category 3 (red), category 2 (orange), category 1 (yellow), tropical storm (green), tropical depression (blue), and extratropical (gray). Note that cases are not LOT or ROT for their entire lifecycle; they must first meet the criteria defined in section 1 . 
Table 2. TCs (1979-2014) included in the composite analysis (section 4). The time (UTC), date, and year listed represent the initial time of precipitation distribution shift $(\mathrm{t}=00 \mathrm{~h})$ for the $26 \mathrm{LOT}$ (left) and 22 ROT (right) cases, respectively.

\begin{tabular}{|l|l|l|l|l|l|l|l|}
\hline \multicolumn{3}{|c}{ LOT Cases } & \multicolumn{5}{c|}{ ROT Cases } \\
\hline TC & Time (UTC) & Date & Year & TC & Time (UTC) & Date & Year \\
\hline David & 0600 & 06 Sep & 1979 & Sandy & 1800 & 26 Oct & 2012 \\
\hline Frederic & 1800 & $13 \mathrm{Sep}$ & 1979 & Arthur & 1200 & 04 Jul & 2014 \\
\hline Dennis & 0000 & $20 \mathrm{Aug}$ & 1981 & Bob & 0000 & 12 Jul & 1979 \\
\hline Gloria & 0000 & $27 \mathrm{Sep}$ & 1985 & Claudette & 0600 & 27 Jul & 1979 \\
\hline Charley & 0600 & $18 \mathrm{Aug}$ & 1986 & Alicia & 1800 & 19 Aug & 1983 \\
\hline Hugo & 1200 & $22 \mathrm{Sep}$ & 1989 & Elena & 1800 & 03 Sep & 1985 \\
\hline Andrew & 0000 & $28 \mathrm{Aug}$ & 1992 & Chantal & 0000 & 03 Aug & 1989 \\
\hline Bertha & 0000 & $13 \mathrm{Jul}$ & 1996 & Jerry & 1200 & 16 Oct & 1989 \\
\hline Josephine & 0600 & 08 Oct & 1996 & Gordon & 0000 & 17 Nov & 1994 \\
\hline Danny & 1200 & $24 \mathrm{Jul}$ & 1997 & Erin & 1800 & 04 Aug & 1995 \\
\hline Earl & 0600 & 03 Sep & 1998 & Jerry & 0600 & 27 Aug & 1995 \\
\hline Floyd & 1800 & $15 \mathrm{Sep}$ & 1999 & Fran & 1200 & 06 Sep & 1996 \\
\hline Gordon & 0000 & $18 \mathrm{Sep}$ & 2000 & Helene & 1800 & 22 Sep & 2000 \\
\hline Isidore & 1200 & $26 \mathrm{Sep}$ & 2002 & Allison & 1800 & 05 Jun & 2001 \\
\hline Frances & 0600 & $08 \mathrm{Sep}$ & 2004 & Hanna & 0600 & 14 Sep & 2002 \\
\hline Gaston & 0600 & $31 \mathrm{Aug}$ & 2004 & Kyle & 1800 & 11 Oct & 2002 \\
\hline Ivan & 0000 & $17 \mathrm{Sep}$ & 2004 & Lili & 0600 & 04 Oct & 2002 \\
\hline Jeanne & 1800 & $27 \mathrm{Sep}$ & 2004 & Bill & 0000 & 01 Jul & 2003 \\
\hline Katrina & 1200 & $30 \mathrm{Aug}$ & 2005 & Grace & 1200 & 31 Aug & 2003 \\
\hline Barry & 1800 & $02 \mathrm{Jun}$ & 2007 & Rita & 0000 & 25 Sep & 2005 \\
\hline Gustav & 1200 & $04 \mathrm{Sep}$ & 2008 & Ernesto & 0600 & 01 Sep & 2006 \\
\hline Hanna & 1200 & $06 \mathrm{Sep}$ & 2008 & Erin & 1200 & 18 Aug & 2007 \\
\hline Ike & 1800 & $13 \mathrm{Sep}$ & 2008 & Gabrielle & 0600 & 10 Sep & 2007 \\
\hline Irene & 1800 & $27 \mathrm{Aug}$ & 2011 & Isaac & 0600 & 30 Aug & 2012 \\
\hline
\end{tabular}

mean track of the cases in each composite group (bold white lines in Fig. 4). Similar composite techniques were utilized for transitioning TCs by Hart et al. (2006), Atallah et al. (2007), Milrad et al. (2009), and Kofron et al. (2010a,b), as well as for TC recurvature by Aiyyer (2015).

All variables including the Cyclone Phase Space parameters were composited individually; for example, the EMBGR shown is the composite mean EMBGR, not EMBGR derived from other composite mean mass fields (Atallah et al. 2007; Milrad et al. 2009). We compared composite mean EMBGR with EMBGR calculated from the composite mean components and results were similar. For each case, $\mathrm{t}=00 \mathrm{~h}$ was defined as the time of precipitation shift. The grid-centered technique was applied from $\mathrm{t}=-24 \mathrm{~h}$ to $\mathrm{t}=+24 \mathrm{~h}$ at 6 - $\mathrm{h}$ increments, not solely at $\mathrm{t}=00 \mathrm{~h}$. We stress that the background geography in the grid-centered composite mean plots (Figs. 5-14) is shown for reference only, and that the time evolution and movement of each feature is relative to each respective (LOT and ROT) composite mean track (Fig. 4). Therefore, our composite mean results are presumed to not be topographically influenced because of the diversity in location and intensity of individual cases.

\section{c. Precipitation distribution}

Figure 5 shows composite MSLP, 1000-500$\mathrm{hPa}$ thickness, and 6-h precipitation for LOT cases, 


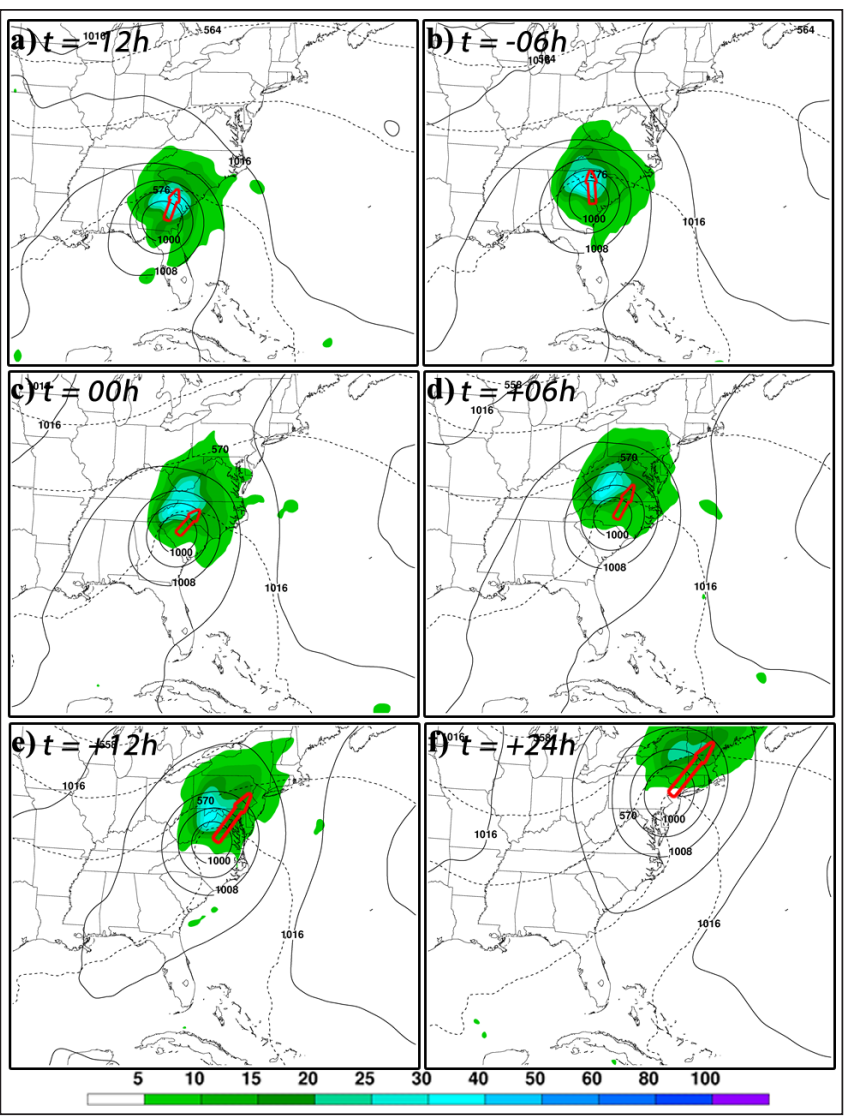

Figure 5. LOT composite from the CFSR: 6-h precipitation (mm, shaded), MSLP ( $\mathrm{hPa}$, solid black contours), and 1000-500-hPa thickness (dam, dashed black contours) at: (a) $\mathrm{t}=-12 \mathrm{~h}$, (b) $\mathrm{t}=-06 \mathrm{~h}$, (c) $\mathrm{t}=$ $00 \mathrm{~h}$, (d) $\mathrm{t}=+06 \mathrm{~h}$, (e) $\mathrm{t}=+12 \mathrm{~h}$, and (f) $\mathrm{t}=+24 \mathrm{~h}$. Precipitation is for the $6 \mathrm{~h}$ starting at each composite time (e.g., precipitation at $\mathrm{t}=00 \mathrm{~h}$ is for $\mathrm{t}=00$ to $+06 \mathrm{~h}$ ). The red arrows represent the direction of the MSLP storm center track, and the length of the arrow represents the distance the MSLP storm center moves from the displayed composite time to the next shown composite time.

while Fig. 6 shows the same for ROT cases. In the LOT composite (Fig. 5), the transitioning TC central MSLP is approximately $8 \mathrm{hPa}$ lower than in the ROT composite (Fig. 6), suggesting that LOT cases are generally stronger. Furthermore, the thickness gradient on the northern side of the transitioning TC is larger in the LOT composite, particularly from $\mathrm{t}=00 \mathrm{~h}$ onward (Figs. $5 \mathrm{c}-\mathrm{f}, 6 \mathrm{c}-\mathrm{f}$ ). This suggests that baroclinicity is larger in LOT cases. Precipitation in the LOT composite undergoes a gradual change from along-track at $\mathrm{t}=-12$ $\mathrm{h}$ (Fig. 5a) to fully LOT at $\mathrm{t}=00 \mathrm{~h}$ (Fig. 5c). From $\mathrm{t}=00$ $\mathrm{h}$ onward (Figs. $5 \mathrm{c}-\mathrm{f}$ ), precipitation is predominantly

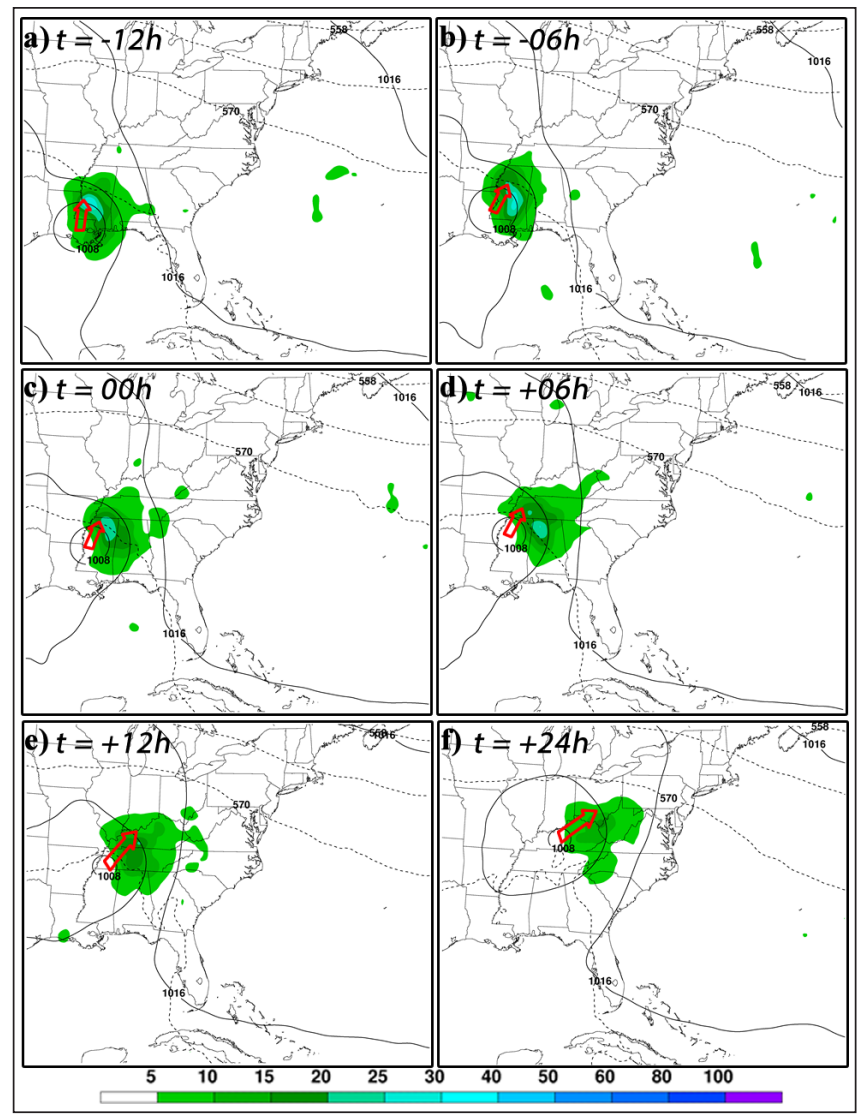

Figure 6. As in Fig. 5, but for the ROT composite.

located in the northwest quadrant of the transitioning TC. This is consistent with Milrad et al. (2009), who found that the heaviest precipitation in LOT cases rotates cyclonically around the transitioning TC near the developing back-bent warm front.

In the ROT composite, precipitation is largely along track at $\mathrm{t}=-12 \mathrm{~h}$ (Fig. $6 \mathrm{a}$ ) but becomes more ROT over time starting at $\mathrm{t}=-06 \mathrm{~h}$ (Figs. $6 \mathrm{~b}-\mathrm{f}$ ). In the LOT composite, precipitation spatial extent expands over time, while in the ROT composite precipitation lessens in amount and areal extent. These findings are consistent with previous research (Atallah et al. 2007; Milrad et al. 2009) and suggest that baroclinic processes are more important in LOT cases by acting to maintain a potent rainfall threat even after TC characteristics have largely vanished. In contrast, ROT cases typically peak at landfall and continue to exhibit some moist convection ROT while they decay slowly due to friction (Hart et al. 2006; Atallah et al. 2007; Milrad et al. 2009; Kofron et al. 2010b). 


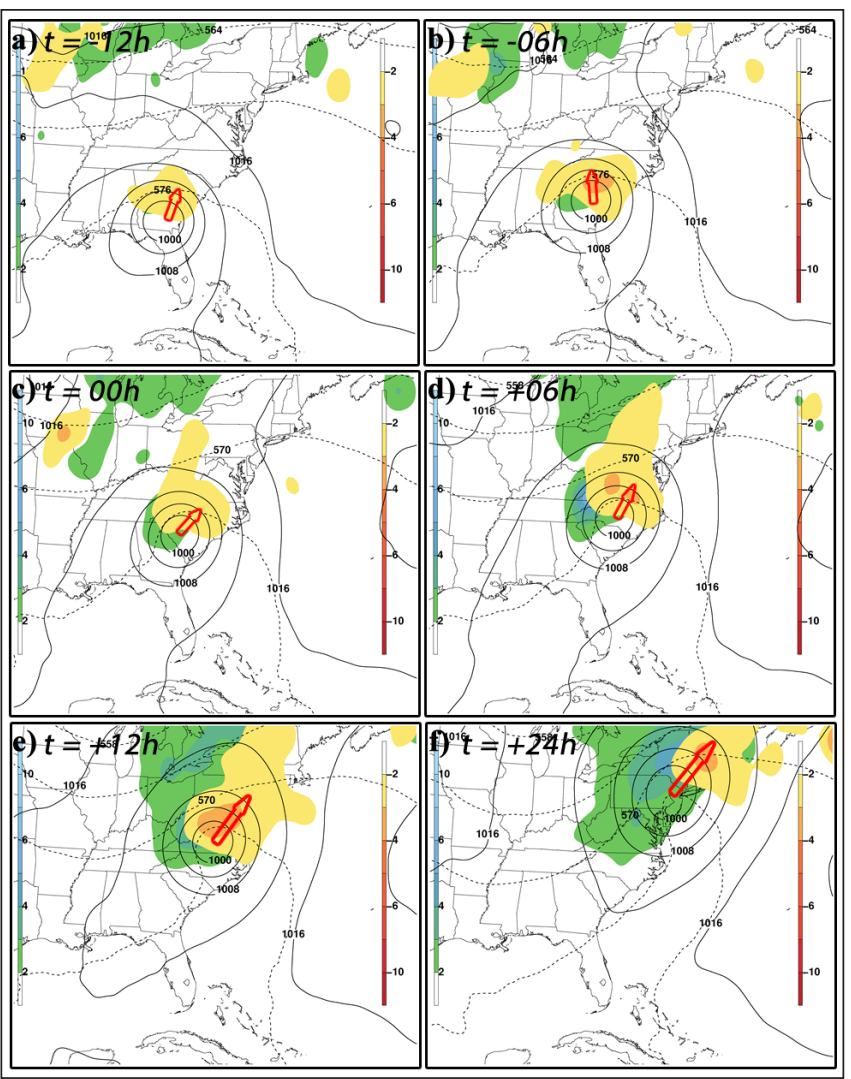

Figure 7. LOT composite from the CFSR: EMBGR (x $10^{-6}$ day $^{-1}$, stable EMBGR shaded in cool colors and MAUL EMBGR in warm colors), MSLP (hPa, solid black contours), and 1000-500-hPa thickness (dam, dashed black contours) at: (a) $\mathrm{t}=-12 \mathrm{~h}$, (b) $\mathrm{t}=-06 \mathrm{~h}$, (c) $\mathrm{t}=00 \mathrm{~h}$, (d) $\mathrm{t}=+06 \mathrm{~h}$, (e) $\mathrm{t}=+12 \mathrm{~h}$, and (f) $\mathrm{t}=$ $+24 \mathrm{~h}$. The red arrows represent the direction of the MSLP storm center track, and the length of the arrow represents the distance the MSLP storm center moves from the displayed composite time to the next shown composite time.

\section{d. EMBGR and components}

Figure $7 \mathrm{a}$ shows that the LOT composite is characterized predominantly by MAUL EMBGR on the north side of the transitioning TC, along track at $\mathrm{t}=-12 \mathrm{~h}$. By $\mathrm{t}=00 \mathrm{~h}$, MAUL EMBGR grows in areal extent and shifts LOT (Figs. 7b,c). Between $t=00 \mathrm{~h}$ and $\mathrm{t}=+12 \mathrm{~h}$ (Figs. 7c-e), MAUL EMBGR continues to increase in magnitude and shifts farther LOT. This implies that moist convection is occurring in the warm frontogenesis region (e.g., Atallah et al. 2007; Milrad et al. 2009). Stable EMBGR also becomes much more prominent during this time period. As the transitioning TC evolves toward a cold-core mid-latitude cyclone by

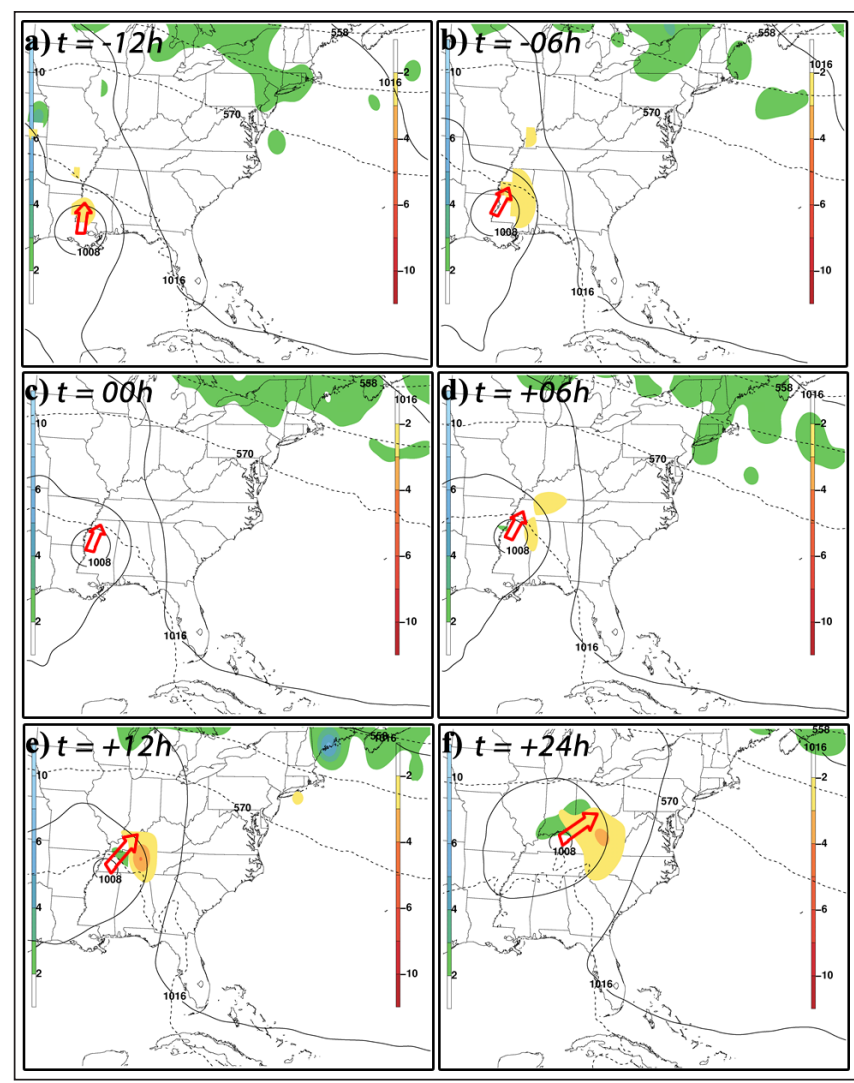

Figure 8. As in Fig. 7, but for the ROT composite.

$\mathrm{t}=+24 \mathrm{~h}$ (Fig. 7f), MAUL EMBGR is overtaken by stable EMBGR in the LOT precipitation region. This suggests a decrease in moist convection around the transitioning TC, emblematic of baroclinic processes starting to dominate. Moreover, the spatial extent of EMBGR also expands over time (Figs. 7b-f); increases in EMBGR areal extent and magnitude are suggestive of large baroclinicity in LOT cases.

In contrast, the ROT composite is characterized by a lack of stable EMBGR and smaller EMBGR spatial extent (Fig. 8). EMBGR is first ROT at $\mathrm{t}=-06 \mathrm{~h}$ (Fig. $8 b$ ). From $t=-06 \mathrm{~h}$ onward (Figs. $8 \mathrm{~b}-\mathrm{f}$ ), relatively weak MAUL EMBGR is located ROT, corresponding to precipitation distribution (Fig. 6). The absence of stable EMBGR throughout the ROT composite (Fig. 8) suggests a relative lack of baroclinicity in ROT cases.

To investigate the sources of EMBGR differences, Figs. 9-12 present the composite evolutions of the two EMBGR components: MBVF and vertical wind shear magnitude. In the LOT composite (Fig. 9), MBVF is predominantly negative (corresponding to MAUL EMBGR) near the transitioning TC through $t=00 \mathrm{~h}$, when an area of positive MBVF (corresponding to stable EMBGR) begins to develop LOT. After $\mathrm{t}=00$ 


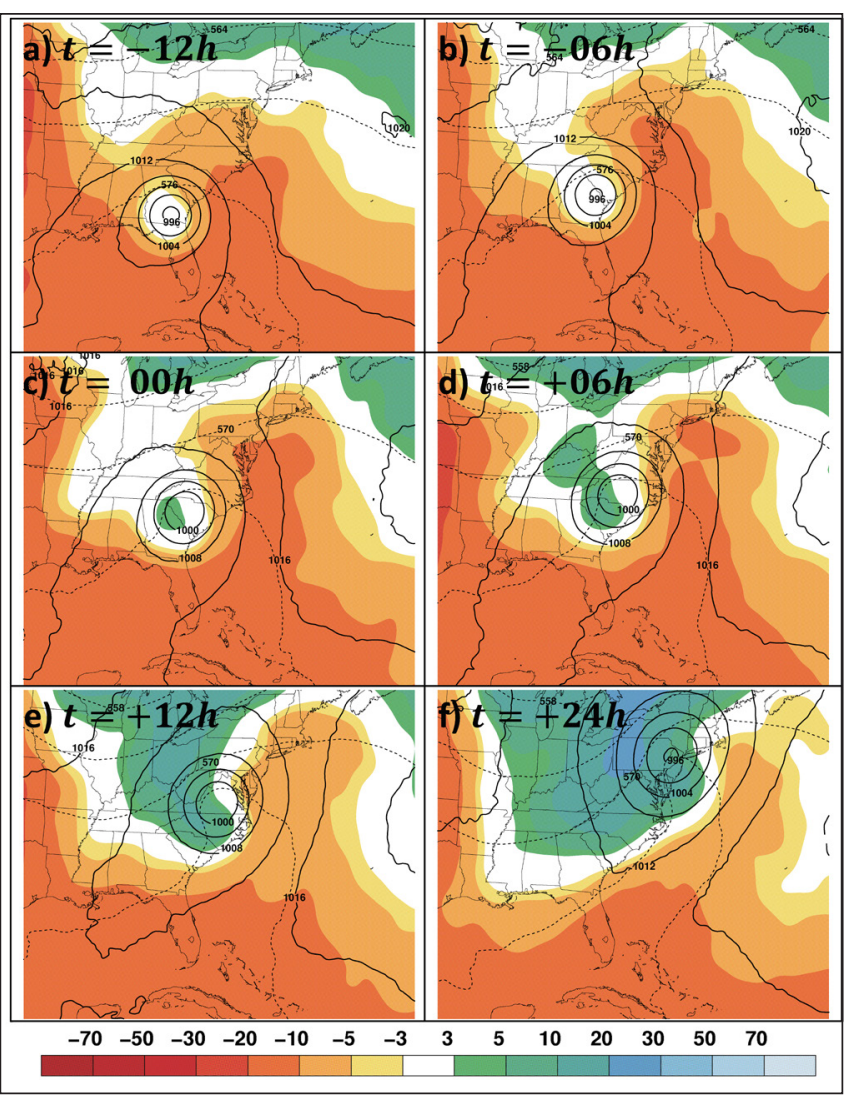

Figure 9. LOT composite from the CFSR: $850-600-\mathrm{hPa}$ layer-averaged MBVF $\left(\times 10^{-6} \mathrm{~s}^{-1}\right.$, cool colors associated with stable EMBGR and warm colors associated with MAUL EMBGR), MSLP (hPa, solid black contours), and 1000-500-hPa thickness (dam, dashed black contours) at: (a) $t=-12 \mathrm{~h}$, (b) $\mathrm{t}=-06 \mathrm{~h}$, (c) $\mathrm{t}=00 \mathrm{~h}$, (d) $\mathrm{t}=+06 \mathrm{~h}$, (e) $\mathrm{t}=+12 \mathrm{~h}$, and (f) $\mathrm{t}=+24 \mathrm{~h}$.

h (Figs. 9c-f), the region of positive MBVF intensifies and expands LOT, corresponding to the increase in stable EMBGR in the same area (Fig. 7). In contrast, negative MBVF is dominant throughout most of the ROT composite evolution (Fig. 10).

Figure 11 shows that vertical wind shear magnitude increases in intensity and areal extent during the LOT composite evolution. At $\mathrm{t}=-12 \mathrm{~h}$ (Fig. 11a), there is weak vertical wind shear located north and northwest of the composite cyclone center, in an environment characterized by negative MBVF (Fig. 9a) and MAUL EMBGR (Fig. 7a). By $\mathrm{t}=00 \mathrm{~h}$, vertical wind shear magnitude increases LOT (Figs. 11c,d), corresponding to the precipitation and EMBGR shifts (Figs. 7, 9). The MBVF and vertical wind shear magnitude signatures in the LOT composite are indicative of an evolving stability environment and increasing baroclinicity during the shift to LOT.

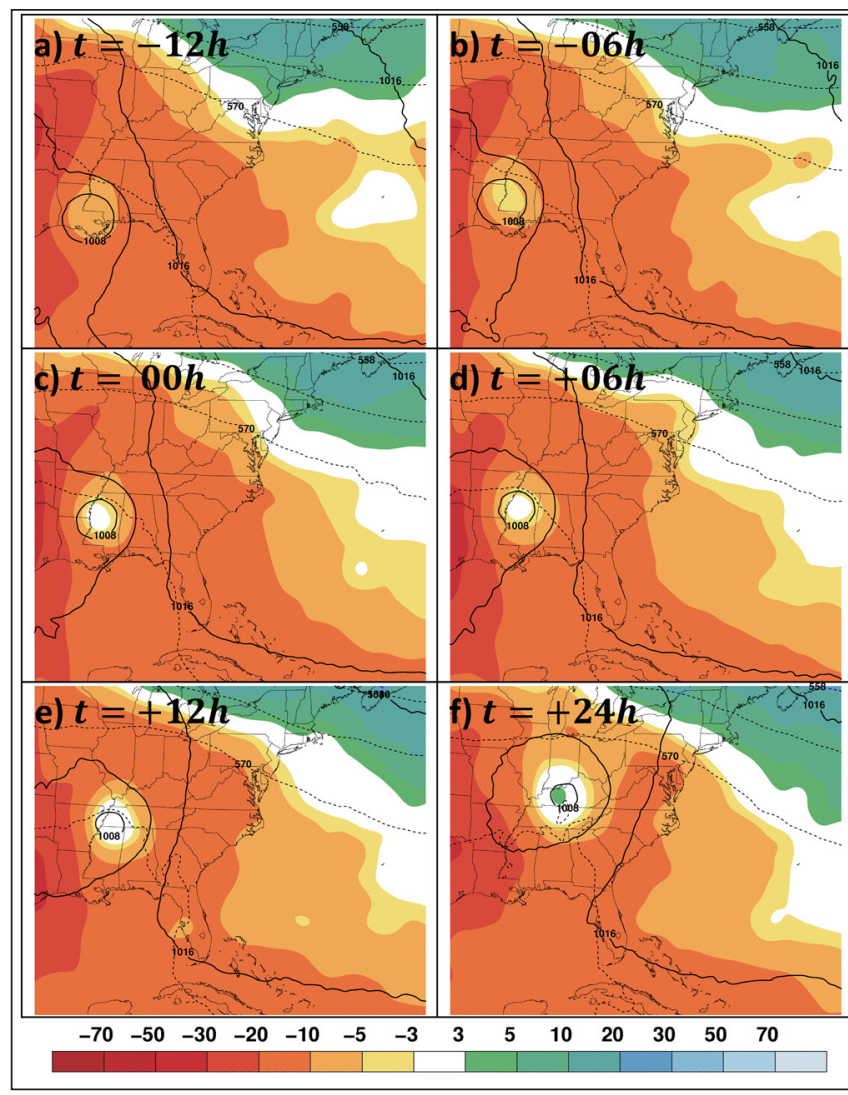

Figure 10. As in Fig. 9, but for the ROT composite.

Neither MBVF nor vertical wind shear magnitude independently diagnoses the evolution of the location of the heaviest precipitation as well as EMBGR does. For example, at $\mathrm{t}=+12 \mathrm{~h}$, the spatial extent of MBVF (Fig. 9e) and vertical wind shear (Fig. 11e) are considerably larger than that of precipitation (Fig. 7e). However, the combined EMBGR metric (Fig. 9e) exhibits better spatial agreement with precipitation than either individual component, and the location of the strongest EMBGR corresponds to the location of the heaviest precipitation. These assertions are generally true throughout the composite evolution, supporting the utility of the EMBGR.

The ROT composite evolutions of MBVF and vertical wind shear magnitude (Figs. 10, 12) are very different from the LOT composite. Negative MBVF dominates throughout (Fig. 10), while little to no vertical wind shear is observed near the transitioning TC until $\mathrm{t}=+12 \mathrm{~h}$ (Fig. 12f). Although negative MBVF is associated with the dominance of MAUL EMBGR in ROT cases (Fig. 8), neither MBVF nor vertical wind shear magnitude diagnoses the ROT shift as well as EMBGR (Figs. 6, 8). This is especially true for the location of the heaviest precipitation after $\mathrm{t}=00 \mathrm{~h}$. 


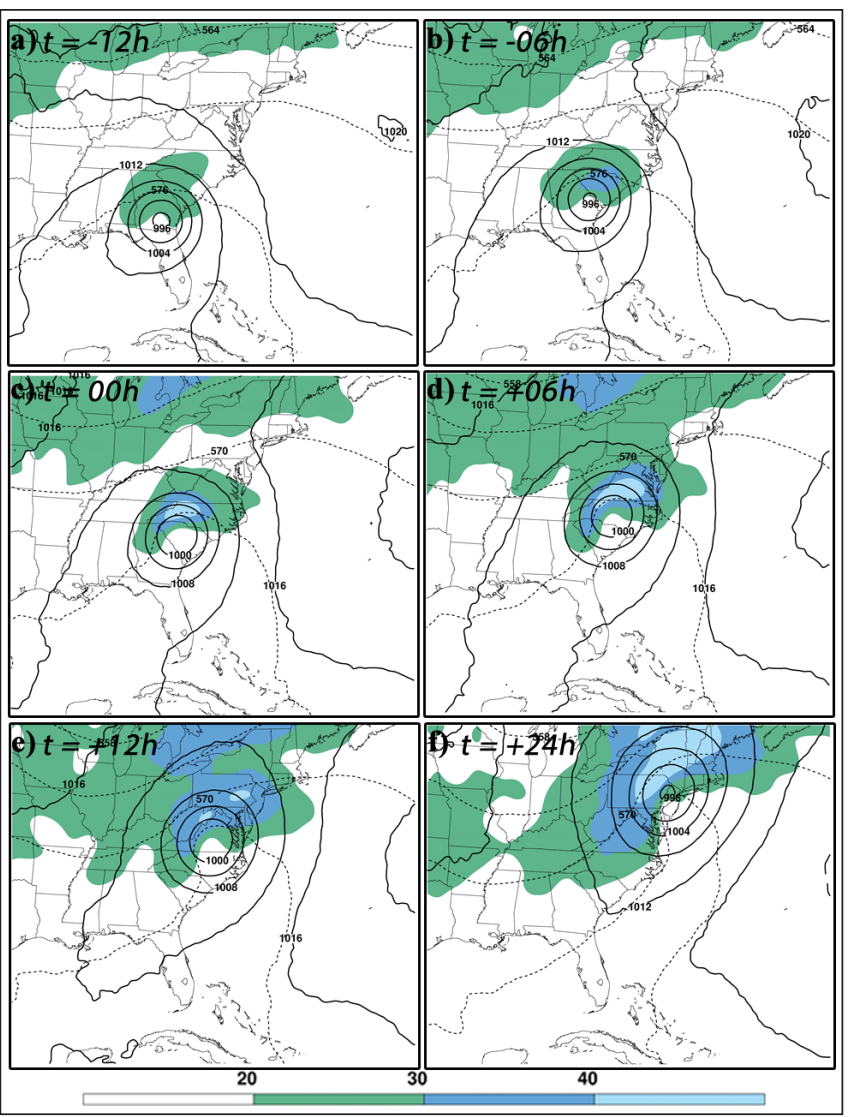

Figure 11. LOT composite from the CFSR: 850-600 $\mathrm{hPa}$ layer-averaged vertical wind shear magnitude (x $10^{-4} \mathrm{~s}^{-1}$, shaded), MSLP ( $\mathrm{hPa}$, solid black contours), and 1000-500-hPa thickness (dam, dashed black contours) at: (a) $\mathrm{t}=-12 \mathrm{~h}$, (b) $\mathrm{t}=-06 \mathrm{~h}$, (c) $\mathrm{t}=00 \mathrm{~h}$, (d) $\mathrm{t}=+06 \mathrm{~h}$, (e) $t=+12 h$ and, (f) $t=+24 h$.

Milrad et al. (2009) found that re-intensifying transitioning TCs exhibited precipitation predominantly LOT in the region of the developing back-bent warm front. Therefore, we tested 2-D frontogenesis as a potential alternative to the EMBGR metric. Figure 13 shows that in the LOT composite, frontogenesis is a good proxy for precipitation distribution (Fig. 5) from $\mathrm{t}=00 \mathrm{~h}$ onward. However, frontogenesis is not a great match with precipitation at $\mathrm{t}=-12$ and $-06 \mathrm{~h}$ (Figs. 13a,b), where it is considerably more ROT. In ROT cases, frontogenesis is weak and lacks a coherent pattern from $\mathrm{t}=-12 \mathrm{~h}$ to $\mathrm{t}=+06 \mathrm{~h}$ (Figs. 14a-d), although it is a better match for precipitation (Fig. 6) at $\mathrm{t}=+06$ and $+12 \mathrm{~h}$ (Figs. 14e,f). Overall, frontogenesis does not a priori diagnose the qualitative shift in precipitation distribution, although it does seem to be a better match at later composite times. We suspect that this is likely related to the shift from MAUL EMBGR to
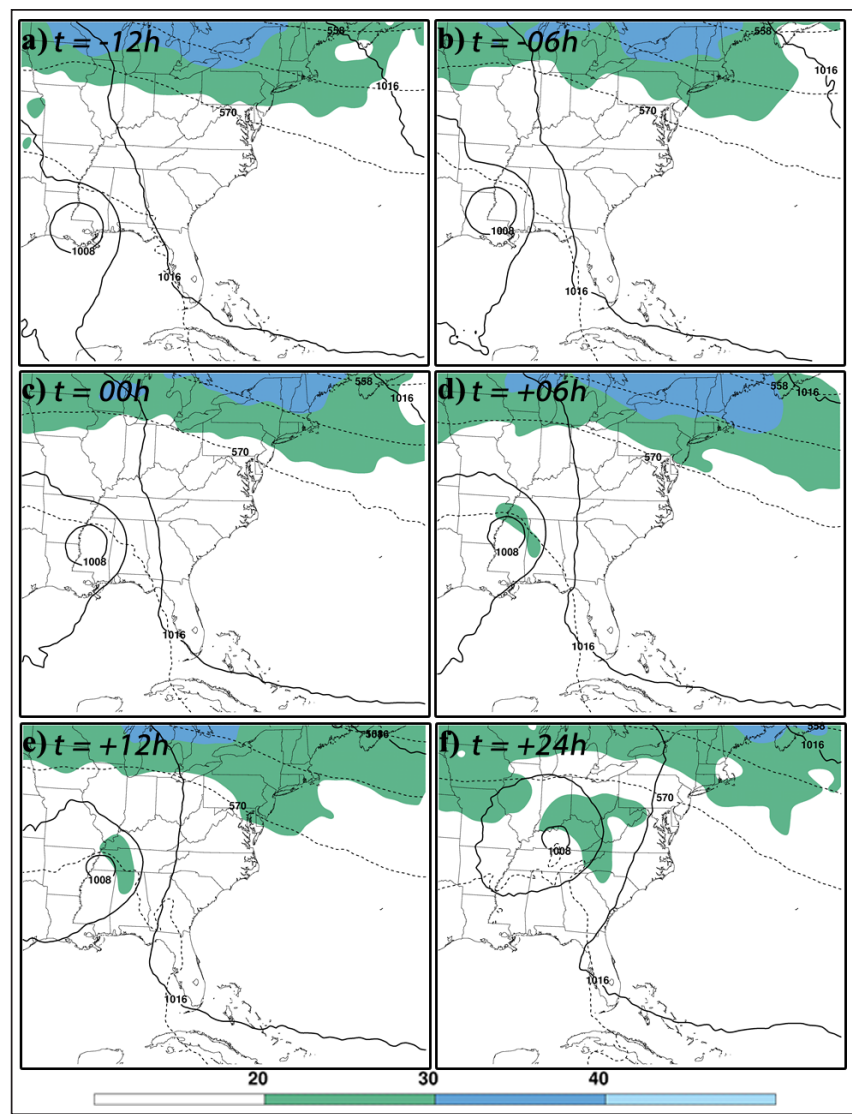

Figure 12. As in Fig. 11, but for the ROT composite.

stable EMBGR throughout the composites, especially in LOT cases. Specifically, areas of MAUL EMBGR primarily represent areas of buoyant forcing for ascent. As buoyancy is lost and dynamic forcing is increasingly required for deep ascent, especially near the developing back-bent warm front in LOT cases, frontogenesis becomes a better proxy for precipitation distribution. However, EMBGR is an overall better qualitative match with precipitation than frontogenesis for the duration of the composites.

\section{e. Cyclone Phase Space}

Composite Cyclone Phase Space diagrams for every $6 \mathrm{~h}$ from $\mathrm{t}=-24 \mathrm{~h}$ to $\mathrm{t}=+24 \mathrm{~h}$ are shown in Fig. 15. Hart et al. (2006) found that TCs that enter the asymmetric warm-core phase are more likely to exhibit re-intensifying ET characteristics such as LOT precipitation. In the LOT composite (Fig. 15a), the transitioning TC first enters the asymmetric warm-core phase at $\mathrm{t}=00 \mathrm{~h}$, roughly corresponding to the LOT precipitation shift. The transitioning TC approaches the asymmetric cold-core phase by $\mathrm{t}=+24 \mathrm{~h}$ (Fig. 15a), 


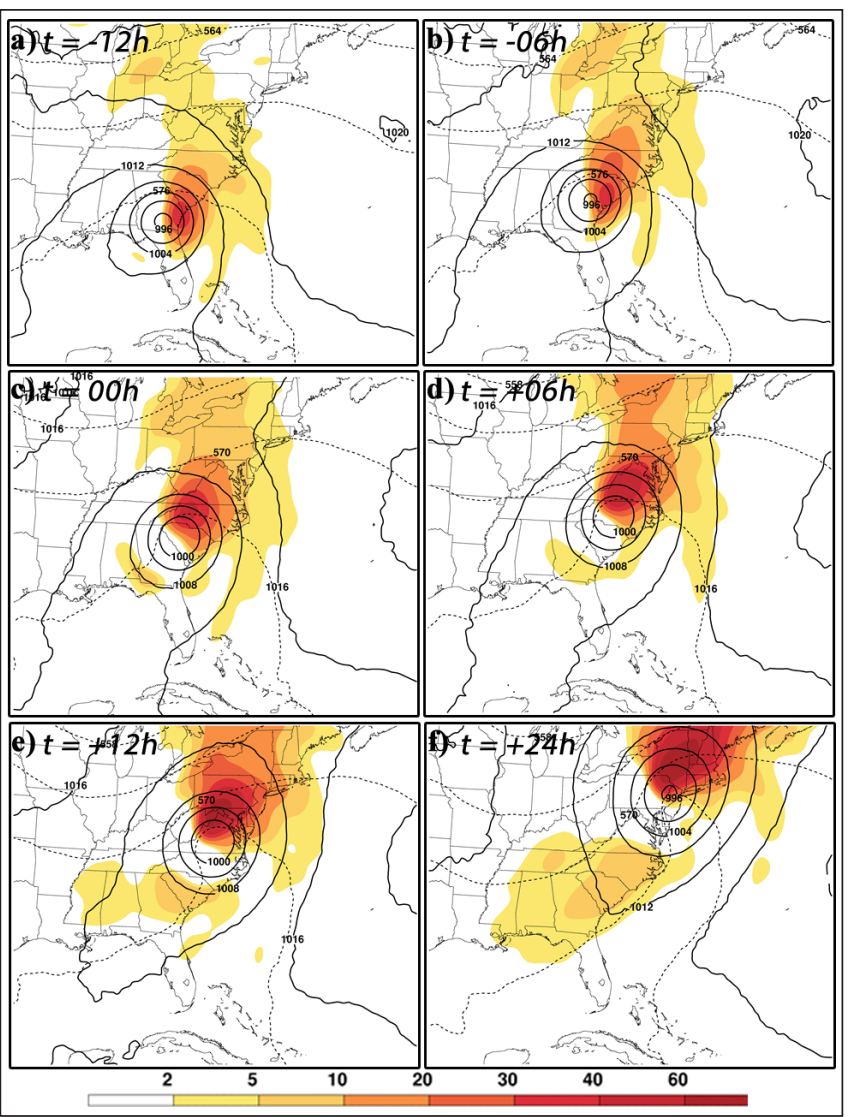

Figure 13. LOT composite from the CFSR: $850-600$ $\mathrm{hPa}$ layer-averaged 2-D frontogenesis $\left(\times 10^{-2} \mathrm{~K} 100 \mathrm{~km}^{-1}\right.$ $3 \mathrm{~h}^{-1}$, shaded), MSLP (hPa, solid black contours), and 1000-500-hPa thickness (dam, dashed black contours) at: (a) $\mathrm{t}=-12 \mathrm{~h}$, (b) $\mathrm{t}=-06 \mathrm{~h}$, (c) $\mathrm{t}=00 \mathrm{~h}$, (d) $\mathrm{t}=+06 \mathrm{~h}$, (e) $t=+12 h$, and (f) $t=+24 h$.

suggesting that ET is nearly complete (Evans and Hart 2003; Hart 2003; Evans et al. 2017).

The ROT Cyclone Phase Space shows that the cyclone generally remains in the symmetric warm-core sector throughout (Fig. 15b). The lack of asymmetry is consistent with smaller baroclinicity in the ROT composite (Figs. 12, 14). Despite the composite result (Fig. 15b), a few of the 22 ROT cases did enter the asymmetric warm-core sector (not shown). This exemplifies the difference between the Cyclone Phase Space and the EMBGR metric; the Cyclone Phase Space is designed to detect time of ET onset and completion, as well as cyclone characteristics (Hart 2003; Hart et al. 2006), while the EMBGR is a proxy for one specific impact i.e., precipitation distribution. As such, we envision the EMBGR serving as a complement to the Cyclone Phase Space.

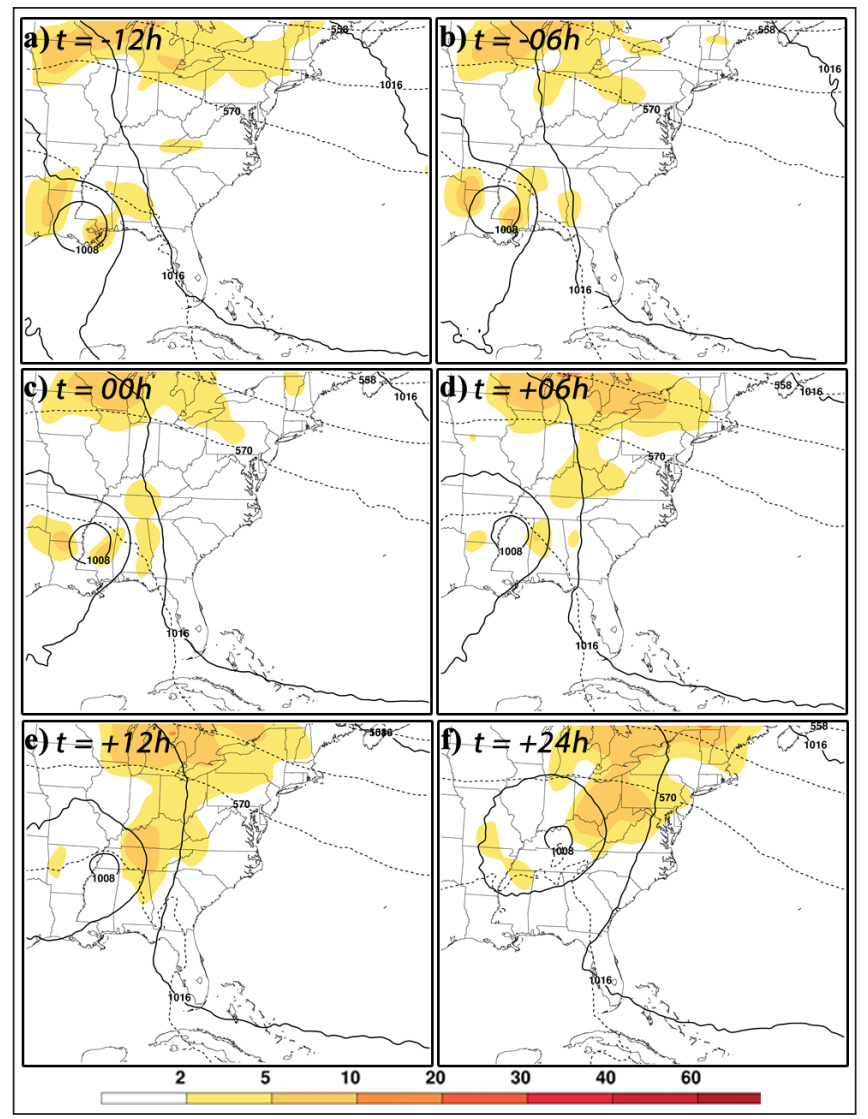

Figure 14. As in Fig. 13, but for the ROT composite.

\section{Discussion and conclusions}

Our case study and composite results demonstrate that the EMBGR can be used as a proxy for precipitation distribution in transitioning TCs. While each EMBGR component (MBVF, vertical wind shear magnitude) differs between LOT and ROT cases, neither is as precise a proxy for precipitation location as the EMBGR metric. To quantify the EMBGR's utility, we calculated the Pearson correlation coefficients between EMBGR and precipitation for the LOT and ROT composites (Fig. 16). Figure 16 only shows correlations between the full EMBGR field (i.e., the total spatial extent of stable and MAUL EMBGR combined) with precipitation. However, we do discuss correlation results for each type of EMBGR below.

Correlation coefficients for both the LOT and ROT composites are between 0.4 and 0.6 during the composite evolutions (Fig. 16). However, there are some subtle but important changes; in the LOT composite, the correlation between total EMBGR and precipitation increases slightly from $t=-12 \mathrm{~h}$ to $\mathrm{t}=-06$ $\mathrm{h}$, likely indicative of the EMBGR's ability to detect 


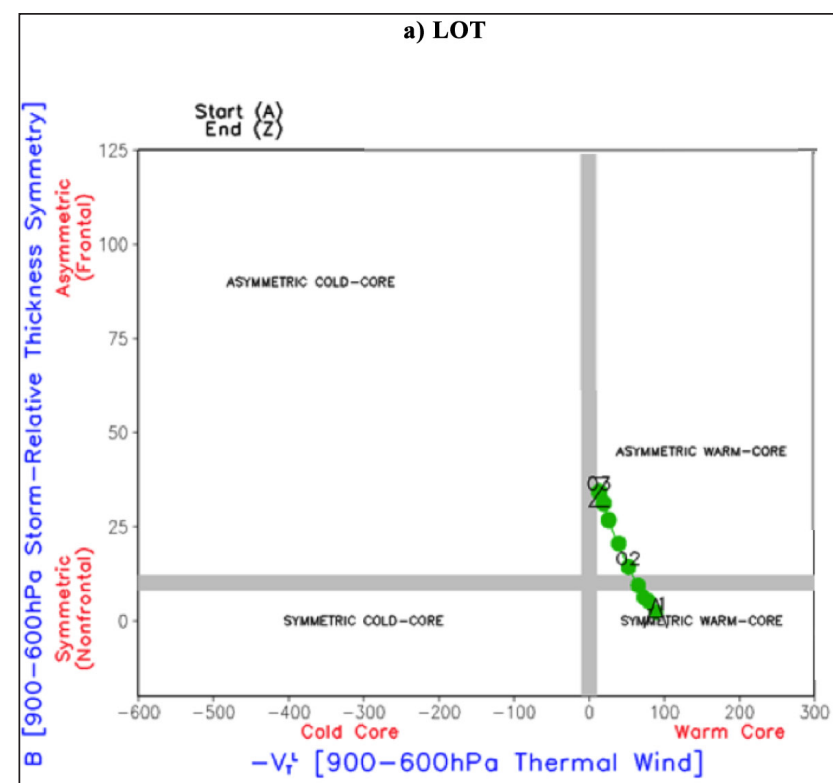

b) ROT

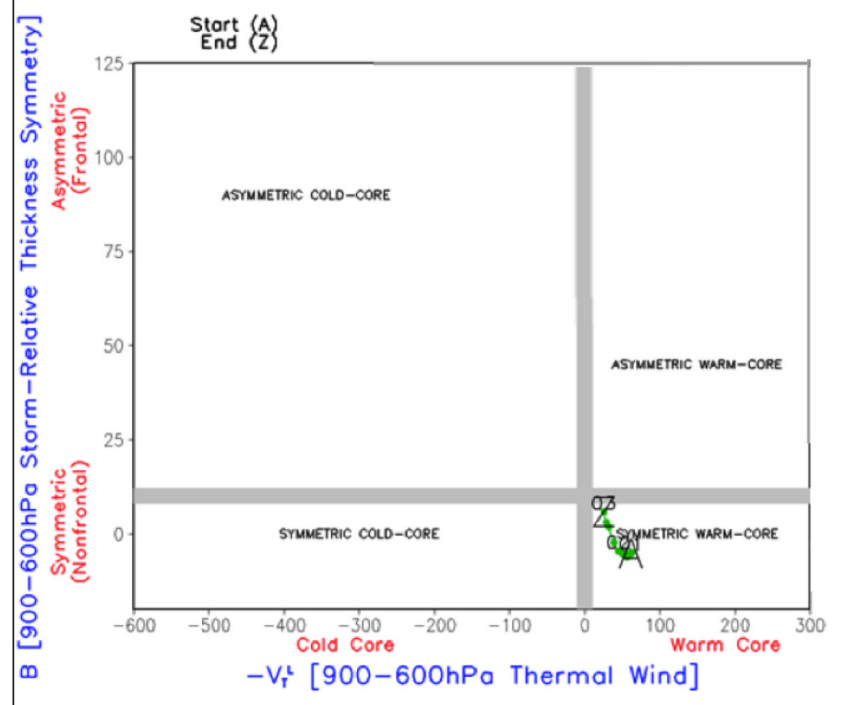

Figure 15. Cyclone Phase Space diagrams (Hart 2003) from the CFSR for the (a) LOT and (b) ROT composites. Each green dot represents a 6-h time step from $\mathrm{t}=-24$ $\mathrm{h}$ to $\mathrm{t}=+24 \mathrm{~h}$, inclusive, and the numeric labels 01,02 , and 03 refer to the start of each composite day (i.e., 01 starts at $\mathrm{t}=-24 \mathrm{~h}, 02$ at $\mathrm{t}=00 \mathrm{~h}$, and 03 at $\mathrm{t}=+24 \mathrm{~h}$ ).

the shift to LOT precipitation (section 4). In contrast, the ROT composite correlation decreases between $\mathrm{t}=-12 \mathrm{~h}$ and $\mathrm{t}=00 \mathrm{~h}$ (Fig. 16), suggesting that total EMBGR correlates less strongly with precipitation during the gradual shift to ROT. The ROT correlation does slightly increase again after $\mathrm{t}=00 \mathrm{~h}$ (Fig. 16). Individual correlations between precipitation and stable

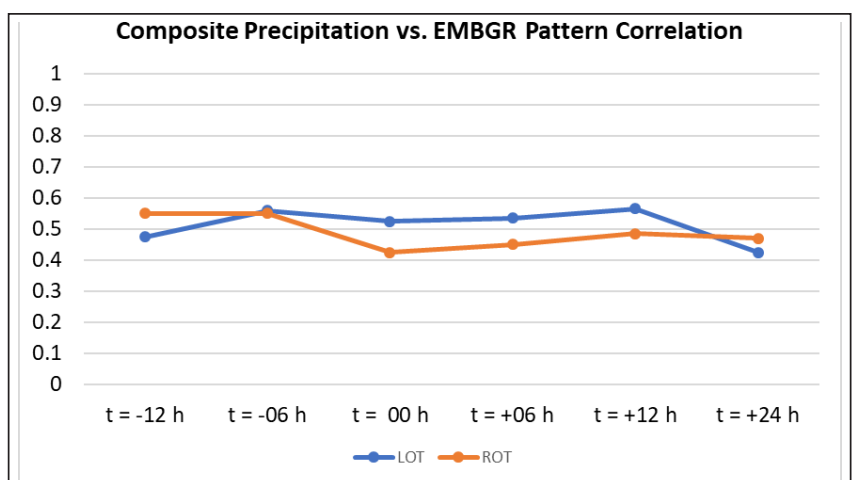

Figure 16. Pearson product-moment correlation coefficients between CFSR composite precipitation and total EMBGR for (blue) LOT and (orange) ROT composites for each time step from $t=-12$ to $t=+24 h$ shown in the composites (Figs. 5-8).

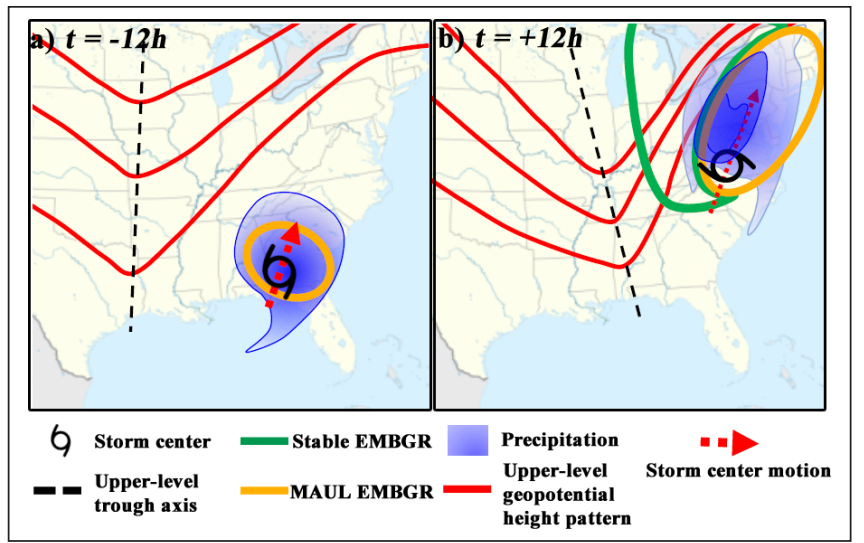

Figure 17. Conceptual schematic for LOT cases at (a) $t=-12 \mathrm{~h}$ and (b) $\mathrm{t}=+12 \mathrm{~h}$. In each panel, the red arrow is storm motion, the solid red contours represent the upper-tropospheric geopotential height pattern, the dashed black line represents the upper-tropospheric trough axis, the green and orange areas represent stable and MAUL EMBGR, respectively, and the blue shaded area is precipitation distribution. In (b), the darker blue shading represents the region of heaviest precipitation.

and MAUL EMBGR, respectively, suggest that LOT precipitation is slightly better correlated with stable EMBGR while ROT precipitation is slightly better correlated with MAUL EMBGR (not shown). This is likely due to the larger impacts of baroclinicity and mid-latitude processes in LOT cases (which stable EMBGR better diagnoses), while ROT cases primarily feature remnant moist convection to the right of the cyclone center (which MAUL EMBGR better detects). We caution, however, that the formulation of the MBVF used here may be less accurate in regions of small static 
stability such as the moist convection associated with the ROT precipitation (Fraser et al. 1973; Durran and Klemp 1982).

In summary, LOT cases exhibit MAUL EMBGR on the northwestern side of the transitioning TC, just prior to and during the shift to LOT precipitation distribution. Over time, stable EMBGR becomes more prominent as the transitioning TC acquires extratropical characteristics. Examinations of radar and satellite imagery (not shown) confirm that this is likely due to a negative time tendency in moist convection in the warm frontogenesis region. As transition occurs, moist convection (i.e., MAUL EMBGR) is present in the warm frontogenesis region. Once transition is complete and the $\mathrm{TC}$ is a cold-core cyclone, moist convection is no longer present and therefore stable EMBGR is dominant, representative of strong baroclinicity in a statically stable atmosphere.

In ROT cases, MAUL EMBGR is observed ROT just prior to the precipitation shift, but stable EMBGR is not seen. Baroclinity is weak, which leads to the TC eventually decaying due to friction. Although ROT cases tend to produce less rainfall and fewer impacts to life and property than LOT cases, they can still cause substantial precipitation. MAUL EMBGR is still able to detect the ROT precipitation signal in these cases due to its utility as a proxy for small static stability and moist convection.

To aid forecasters, Fig. 17 displays a schematic for LOT cases, which typically have the largest impact on life and property (Atallah et al. 2007; Milrad et al. 2009). The schematic shows the evolution of a typical LOT case from $\mathrm{t}=-12$ to $\mathrm{t}=+12 \mathrm{~h}$. At $\mathrm{t}=-12 \mathrm{~h}$, a midlatitude upper-level trough approaches from the west (Fig. 17a). At the same time, precipitation and MAUL EMBGR are limited to the region just north of the TC, largely along track. However, by $\mathrm{t}=+12 \mathrm{~h}$ (Fig. 17b), precipitation shifts LOT, the spatial extent of EMBGR increases, and stable EMBGR becomes more prominent as baroclinic processes start to dominate.

Following the qualitative analysis presented here, future work will evaluate EMBGR statistics and its applicability to predictability in deterministic and ensemble numerical weather prediction systems. EMBGR evaluations should also be expanded to other TC basins such as the Western North Pacific. The Western North Pacific sees similar impacts from the LOT rainfall of transitioning TCs in denselypopulated Japan (e.g., Evans et al. 2017). To further aid forecasters, threshold values of EMBGR for each composite type should also be calculated. Finally, numerical model forecasts of EMBGR should be tested for many other cases to determine whether, as in the case of Matthew (2016), EMBGR offers predictability advantages over model QPF. The use of reforecasts would facilitate this endeavor in retrospective mode, elucidating correlations between model EMBGR/QPF and observed precipitation for historical cases.

Note. Tomer Burg has produced publicly available real-time EMBGR analysis and forecast products. The EMBGR product may be accessed through Tomer Burg's webpage http://www.atmos.albany.edu/student/ tburg/.

Acknowledgments. This research was primarily supported by an internal research grant from EmbryRiddle Aeronautical University's Honors Program. The authors would like to extend their gratitude to Dr. Anantha Aiyyer of North Carolina State University for providing grid-centered composite scripts, Dr. Robert Hart of Florida State University for making the Cyclone Phase Space code publicly available, Rachael Isphording for help with the correlation analysis, and Shealynn Cloutier-Bisbee for research assistance. The authors thank Dr. Eyad Atallah and Dr. John Gyakum of McGill University, and Dr. Lynn McMurdie of the University of Washington for providing helpful advice and comments on earlier versions of this manuscript. Finally, we are indebted to the four anonymous reviewers and editor Dr. Andrew Molthan for their valuable comments and edits to earlier versions of this manuscript.

\section{REFERENCES}

Aiyyer, A., 2015: Recurving Western North Pacific tropical cyclones and mid-latitude predictability. Geophys. Res. Lett., 42, 7799-7807.

Atallah, E. H., and L. F. Bosart, 2003: The extratropical transition and precipitation distribution of Hurricane Floyd (1999). Mon. Wea. Rev., 131, 1063-1081.

Atallah, E. H., L. F. Bosart, and A. R. Aiyyer, 2007: Precipitation distribution associated with landfalling tropical cyclones over the eastern United States. Mon. Wea. Rev., 135, 2185-2206. 
Chen, S. S., J. A. Knaff, and F. D. Marks Jr., 2006: Effects of vertical wind shear and storm motion on tropical cyclone rainfall asymmetries deduced from TRMM. Mon. Wea. Rev., 134, 3190-3208.

Cordeira J. M., and L. F. Bosart, 2010: The antecedent largescale conditions of the "Perfect Storms" of late October and early November 1991. Mon. Wea. Rev., 138, 25462569.

Doty, B., and J. L. Kinter III, 1992: The Grid Analysis and Display System (GrADS): A practical tool for earth science visualization. Eighth International Conference on Interactive Information and Procession Systems, Atlanta, Georgia, 5-10 January 1992.

Durran, D. R., and J. B. Klemp, 1982: On the effects of moisture on the Brunt-Väisälä frequency. J. Atmos. Sci., 39, 2152-2158.

Eady, E., 1949: Long waves and cyclone waves. Tellus, 1, 33-52.

Evans, C., and R. E. Hart, 2008: Analysis of the wind field evolution associated with the extratropical transition of Bonnie (1998). Mon. Wea. Rev., 136, 2047-2065.

Evans, C., and Coauthors, 2017: The extratropical transition of tropical cyclones. Part I: Cyclone evolution and direct impacts. Mon. Wea. Rev. 145, 4317-4344.

Evans, J. L., J. M. Arnott, and F. Chiaromonte, 2006: Evaluation of operational model cyclone structure forecasts during extratropical transition. Mon. Wea. Rev., 134, 3054-3072.

Evans, J. L., and R. E. Hart, 2003: Objective indicators of the life cycle evolution of extratropical transition for Atlantic tropical cyclones. Mon. Wea. Rev., 131, 909925.

Fraser, A. B., R. C. Easter, and P. V. Hobbs, 1973: A theoretical study of the flow of air and fallout of solid precipitation over mountainous terrain. Part I: Airflow model. $J$. Atmos. Sci., 30, 801-812.

Fritsch, J. M., and R. E. Carbone, 2004: Improving Quantitative Precipitation Forecasts in the warm season: A USWRP research and development strategy. Bull. Amer. Meteor. Soc., 85, 955-965.

Galarneau Jr, T. J., C. A. Davis, and M. A. Shapiro, 2013: Intensification of Hurricane Sandy (2012) through extratropical warm core seclusion. Mon. Wea. Rev., 141, 4296-4321.

Gyakum, J. R., 2008: The application of Fred Sanders' teaching to current research on extreme cold-season precipitation events in the Saint Lawrence River Valley region. Meteorological Monographs, 33, 241-250.

Harr, P., and R. Elsberry, 2000: Extratropical transition of tropical cyclones over the western North Pacific. Part I: Evolution of structural characteristics during the transition process. Mon. Wea. Rev., 128, 2613-2633.
Harr, P., R. Elsberry, and T. Hogan, 2000: Extratropical transition of tropical cyclones over the western North Pacific. Part II: The impact of midlatitude circulation characteristics. Mon. Wea. Rev., 128, 2634-2653.

Hart, R. E., 2003: A Cyclone Phase Space derived from thermal wind and thermal symmetry. Mon. Wea. Rev. 131, 585-616.

Hart, R. E., and J. L. Evans, 2001: A Climatology of the extratropical transition of Atlantic tropical cyclones. $J$. Climate, 14, 546-564.

Hart, R. E., J. L. Evans, and C. Evans, 2006: Synoptic composites of the extratropical transition life cycle of North Atlantic tropical cyclones: Factors determining posttransition evolution. Mon. Wea. Rev., 134, 553-578.

Hoskins, B. J., and P. J. Valdes, 1990: On the existence of storm-tracks. J. Atmos. Sci., 47, 1855-1864.

Huffman, G. J., D. T. Bolvin, and E. J. Nelkin, 2015: Day 1 IMERG final run release notes. NASA Doc., 9 pp., https://pmm.nasa.gov/sites/default/files/document_files/ IMERG_FinalRun_Day1_release_notes.pdf.

Koch, S., M. DesJardins, and P. Kocin, 1983: An interactive Barnes objective map analysis scheme for use with satellite and conventional data. J. Appl. Meteor., 22, 1487-1503.

Kofron, D. E., E. A. Ritchie, and J. S. Tyo, 2010a: Determination of a consistent time for the extratropical transition of tropical cyclones. Part I: Examination of existing methods for finding "ET Time". Mon. Wea. Rev., 138, 4328-4343.

Kofron, D. E., E. A. Ritchie, and J. S. Tyo, 2010b: Determination of a consistent time for the extratropical transition of tropical cyclones. Part II: Potential vorticity metrics. Mon. Wea. Rev., 138, 4344-4361.

Landsea, C. W., and J. L. Franklin, 2013: Atlantic hurricane database uncertainty and presentation of a new database format. Mon. Wea. Rev., 141, 3576-3592.

Lin, Y., and K. E. Mitchell, 2005: The NCEP Stage II/ IV hourly precipitation analyses: Development and applications. Preprints, 19th Conf. on Hydrology, San Diego, CA Amer. Meteor. Soc., 1.2, http://ams.confex. com/ams/pdfpapers/83847.pdf.

Lonfat, M. F., F. D. Marks Jr., and S. S. Chen, 2004: Precipitation distribution in tropical cyclones using the Tropical Rainfall Measuring Mission (TRMM) microwave imager: A global perspective. Mon. Wea. Rev., 132, 1645-1660.

Mesinger, F., and Coauthors, 2006: North American Regional Reanalysis. Bull. Amer. Meteor. Soc., 87, 343-360.

Milrad, S. M., J. R. Gyakum, and E. H. Atallah, 2009: Dynamical and precipitation structures of poleward moving tropical cyclones in eastern Canada, 1979-2005. Mon. Wea. Rev., 137, 836-851. 
Milrad, S. M., J. R. Gyakum, and E. H. Atallah, 2015: A meteorological analysis of the 2013 Alberta Flood: Antecedent large-scale flow pattern and synopticdynamic characteristics. Mon. Wea. Rev., 143, $2817-$ 2841.

National Oceanic and Atmospheric Administration Coastal Services Center (NOAA CSC), 2018: Historical hurricane tracks, Accessed 15 January 2018, https:// coast.noaa.gov/hurricanes/.

National Oceanic and Atmospheric Administration National Centers for Environmental Information (NOAA NCEI), 2018: Billion-dollar weather/climate disasters. Accessed 2 February 2018, https://www.ncdc.noaa.gov/billions/ events]

National Weather Service Weather Prediction Center (NWS WPC), 2018: Tropical cyclone rainfall data. Accessed 2 February 2018, http://www.wpc.ncep.noaa.gov/tropical/ rain/tcrainfall.html.

Ritchie, E. A., and R. L. Elsberry, 2003: Simulations of the extratropical transition of tropical cyclones: Contributions by the midlatitude upper-level trough to reintensification. Mon. Wea. Rev., 131, 2112-2128.

Ritchie, E. A., and R. L. Elsberry, 2007: Simulations of the extratropical transition of tropical cyclones: Phasing between the upper-level trough and tropical cyclone. Mon. Wea. Rev., 135, 862-876.

Roebber, P. J., and L. F. Bosart, 1998: The sensitivity of precipitation to circulation details. Part I: An analysis of regional analogs. Mon. Wea. Rev., 126, 437-455.

Saha, S., and Coauthors, 2010: The NCEP Climate Forecast System Reanalysis. Bull. Amer. Meteor. Soc., 91, 10151057.

Saha, S., and Coauthors, 2014: The NCEP Climate Forecast System Version 2. J. Climate, 27, 2185-2208.

Sisson, P. A., and J. R. Gyakum, 2004: Synoptic-scale precursors to significant cold-season precipitation events in Burlington, Vermont. Wea. Forecasting, 19, 841-854.

Sukovich, E. M., F. M. Ralph, F. E. Barthold, D. W. Reynolds, and D. R. Novak, 2014: Extreme quantitative precipitation forecast performance at the Weather Prediction Center from 2001 to 2011. Wea. Forecasting, 29, 894-911.

The NCAR Command Language (Version 6.5.0) [Software], 2018. Boulder, Colorado: UCAR/NCAR/CISL/TDD. http://dx.doi.org/10.5065/D6WD3XH5.

Vermont Agency of Natural Resources, 2018: Climate change team. Tropical Storm Irene by the numbers, Accessed 2 February 2018, http://www.anr.state.vt.us/anr/ climatechange/irenebythenumbers.html. 